Revista lus et Praxis, Año 21, No 1, 2015, pp. 617 - 650

ISSN 0717 - 2877

Universidad de Talca - Facultad de Ciencias Jurídicas y Sociales

"La cuantificación de la rebaja del precio en la acción quanti minoris"

Pamela Prado López

Colaboración recibida el 15 de mayo y aprobada el 5 de julio de 2014

LA CUANTIFICACIÓN DE LA REBAJA

DEL PRECIO EN LA ACCIÓN QUANTI MINORIS*

Pamela Prado López ${ }^{* *}$

\title{
Ideas preliminares
}

Entre los múltiples problemas teóricos y prácticos que genera la protección jurídica al comprador insatisfecho, el alcance de las acciones edilicias continúa ocupando a buena parte de la doctrina, muchos de los cuales aluden a la acción quanti minoris, de rebaja o reducción del precio. En efecto, la acción quanti minoris ha generado profundos debates entre los autores extranjeros; desde la determinación de su naturaleza, pasando por las relaciones que se producen entre ella con las demás acciones contractuales a fin de resolver si existe o no un orden de prelación; o la discusión en torno a si la acción de rebaja del precio es susceptible de ser aplicada en todo contrato y no sólo en aquellos en que se encuentra expresamente regulada; hasta la forma de cálculo aplicable en la rebaja, han sido cuestiones frecuentemente discutidas; cuestiones, sin embargo, que no han concitado el mismo interés en el derecho nacional. Por ello, es que este trabajo tiene por finalidad referir a uno de aquellos aspectos: los parámetros o factores que pueden ser aplicados al momento de llevarse a cabo la rebaja o reducción del precio en nuestro derecho. De paso, haremos referencia a la naturaleza de la acción quanti minoris, puesto que incide en la identificación de tales parámetros.

Una primera verificación, es que en el derecho nacional, y más precisamente en el Código Civil chileno, no se establece un sistema de cálculo aplicable a la acción de rebaja del precio, lo que ha llevado a los operadores jurídicos a recurrir a sumas alzadas para justificar la rebaja de precio que se demanda, sin mayores antecedentes; y a los sentenciadores a utilizar cantidades fijadas en forma discrecional, lo que dificulta la aplicación de esta

* Este trabajo es una versión ampliada de la ponencia presentada en las XI Jornadas Nacionales de Derecho Civil organizadas por la U. Austral, realizadas entre los días 3 y 5 de octubre del año 2013.

** Profesora de Derecho Civil, Escuela de Derecho, Universidad de Valparaíso, Valparaíso, Chile. Doctora en Derecho (Universidad de Chile, Chile). Dirección postal: Avenida Errázuriz No 2120, Valparaíso, Chile. Correo electrónico: pamela.prado@uv.cl. 
acción. Por ello, es que el objetivo de este análisis es identificar aquellos criterios que pueden ser utilizados por los tribunales de justicia a la hora de dar lugar a la acción de reducción del precio, los que, además, debieren ser explicitados en la sentencia respectiva. Adicionalmente, nos proponemos dar un vistazo a los diversos sistemas de cuantificación en la rebaja de precio en el derecho extranjero y uniforme, como asimismo, evaluar la pertinencia de establecer un mecanismo similar a alguno de aquellos sistemas, como aquel que recientemente se propone en los Principios latinoamericanos de derecho de los contratos.

En el derecho civil chileno, como se sabe, la acción quanti minoris no sólo está expresamente prevista en el contrato de compraventa, sino también en el arrendamiento, coherente con el tratamiento llevado a cabo por el derecho romano $^{1}$. De igual forma, aunque no será desarrollado en este trabajo, somos de la opinión que la acción de rebaja de precio no sólo se puede ejercer en esos dos contratos, sino también en todo aquel cuya naturaleza lo permita, es decir, en contratos bilaterales de los cuales emanen prestaciones susceptibles de ser rebajadas o reducidas, si la prestación o prestaciones de la contraparte, cualquiera sea su naturaleza, ha sido cumplida imperfectamente, acorde a las tendencia en el derecho contemporáneo ${ }^{2}$. De manera tal, que aunque en este estudio nos situaremos específicamente en los casos en que la rebaja se encuentra explícitamente tratada, nos parece que algunos aspectos que se aborden pueden llegar a tener una aplicación más amplia.

\footnotetext{
1 Así, en los artículos 1928 y 1930 del Código Civil. En efecto, en el derecho romano, la acción también se contemplaba para el contrato de arrendamiento, según consta en Digesto del Cuerpo del Derecho Civil Romano (1889-1898): Instituta-Digesto. $1^{\text {a }}$ parte (traducc. Ildefonso L. García del Corral, Barcelona, Jaime Molinas Editor), p. 971.

2 32. Se visualiza en los PECL que regulan este remedio con un alcance más amplio en su artículo 9:401 section 4: Price Reduction. Article 9:401: Right to Reduce Price. (1) A party who accepts a tender of performance not conforming to the contract may reduce the price. This reduction shall be proportionate to the decrease in the value of the performance at the time this was tendered compared to the value which a conforming tender would have had at that time. (2) A party who is entitled to reduce the price under the preceding paragraph and who has already paid a sum exceeding the reduced price may recover the excess from the other party. (3) A party who reduces the price cannot also recover damages for reduction in the value of the performance but remains entitled to damages for any further loss it has suffered so far as these are recoverable under Section 5 of this Chapter". También con un carácter de remedio general se contiene en el Draf Common Frame of Reference, cfr. III. 3:601. Por el contrario, no se encuentra reconocida en los Principios UNIDROIT, ni siquiera en su última versión correspondiente al año 2010. En el caso del derecho interno, destaca con una mayor amplitud en su aplicación, el Código Civil peruano de 1984, que regula la obligación de saneamiento de vicios ocultos -de igual forma que de la evicción- respecto de contratos relativos a la transferencia de la propiedad, la posesión o el uso de un bien, conforme al artículo 1484, en cuyo caso, el acreedor puede ejercer acción redhibitoria o estimatoria.
} 


\section{Algunas generalidades sobre la acción quanti minoris, de rebaja o reducción del precio}

\subsection{El origen de la acción quanti minoris y su establecimiento en el Código Civil chileno}

La acción de rebaja de precio se remonta al derecho romano, específicamente en la protección dispensada por los ediles curules al comprador. El sistema contenido en las acciones edilicias se compone de dos acciones que aún mantienen las denominaciones de raíz románica: la redhibitoria y la quanti minoris o estimatoria ${ }^{3}$; la primera con la finalidad de recuperar el precio a través de la restitución de la cosa comprada, y la segunda, con el objeto de reducir el montante del precio pagado, atendido el vicio que tiene la cosa vendida, quedando a la entera elección del comprador la acción que éste ejerza.

En las Partidas se mantiene un sistema similar de acciones, destacando que desde ya se suscita la discusión en orden a la modalidad de cómputo de la rebaja del precio ${ }^{4}$. Las acciones edilicias pasan, así, al derecho francés y luego al nuestro.

Sin embargo, hay que destacar que la reglamentación de las acciones edilicias contenida en el Code presenta algunas diferencias con la forma en que fueron incorporadas en nuestro Código Civil. En efecto, en el Código Civil francés de conformidad al artículo 1641 el comprador tendrá derecho al saneamiento de la cosa en razón de vicios ocultos, ya sea para el caso en que el comprador no la hubiere adquirido, o hubiera pagado un menor precio por ella, y en ambas situaciones tiene derecho a optar, bien por la redhibición, bien por la

\footnotetext{
3 "Si el vendedor hubiere afirmado alguna cosa respecto a un esclavo, y el comprador se quejase que este no era así, puede ejercer la acción redhibitoria o la estimatoria, esto es, la quanti minoris; por ejemplo, si hubiese afirmado que era constante, o laborioso o diligente, o vigilante, o que con su frugalidad adquiriría peculio, y él por el contrario hallara que era ligero, protervo, desidioso, dormilón perezoso, pesado y comilón; respecto de todo esto parece corresponde, que lo que el vendedor hubiere afirmado no sea exigido por él rigurosamente, sino con cierta moderación, de suerte que si acaso hubiera afirmado que es constante, no se exija exacta gravedad y circunstancia, como de un filósofo, y si hubiere afirmado que era laborioso y vigilante, no se exija de él continua labor de día y noche; sino que todo esto se reclama moderadamente según bondad y equidad. Lo mismo entenderemos también respecto de lo demás que el vendedor hubiese afirmado". 18. GaYo, Comentarios al Edicto de los Ediles Curules. Libro I. Digesto del Cuerpo del Derecho Civil Romano (1889-1898): Instituta-Digesto. $1^{\text {a }}$ parte (Traducc. Ildefonso L. García del Corral, Barcelona, Jaime Molinas Editor).

${ }^{4}$ Morales Moreno, Antonio (1980): "El alcance protector de las acciones edilicias", en: Anuario de derecho civil (fascículo III), p. 605. En efecto, como en las Partidas también se produjo una superposición entre las acciones edilicias y las civiles, para algunos, en la acción civil la reducción debía hacerse atendiendo a la diferencia entre lo que se dio por la cosa y lo que se hubiese ofrecido por ella, en tanto que en la acción honoraria se debía considerar la diferencia entre el precio pactado y el valor real.
} 
disminución del precio, como establece el artículo $1644^{5}$. Normas parecidas se contienen en el Código español ${ }^{6}$. Este sistema ha sido fuertemente criticado tanto en Francia como en España, debido a que habría una inconsistencia al permitir al comprador, a su entero arbitrio, pedir que el contrato se deje sin efecto incluso en el caso que la compraventa se hubiere celebrado igualmente, pero a un menor precio, esto es, aun ante defectos nimios. No obstante, este problema se habría corregido por la doctrina y la jurisprudencia, a través del mecanismo de exigir la gravedad del defecto, solución que, empero, conlleva cierto peligro pues si se considera que el vicio no es grave, no sólo se priva al comprador del ejercicio de la acción redhibitoria, sino también de la quanti minoris ${ }^{7}$. La explicación de esta decisión del codificador francés, recuerda un autor, estaría en el hecho de que en la redacción de las normas del Code habría estado presente tanto la influencia de Domat, como de Pothier, quienes no suscribían a la misma opinión respecto a la naturaleza del vicio; así, para Pothier el vicio requería siempre cierta gravedad, lo que justificaría un tratamiento unitario de las acciones redhibitoria y quanti minoris, opinión que habría sido la fuente directa de inspiración del artículo 1644. Las ideas de Domat, por el contrario, se plasmaron en la redacción del artículo 1641, según el cual se podría dar

\footnotetext{
${ }^{5}$ En efecto, el artículo 1641 establece que: "El vendedor estará obligado al saneamiento en razón de los vicios ocultos de la cosa que la hicieran impropia para el uso al cual estaba destinada, o que disminuyeran de tal manera dicho uso, que el comprador no la hubiera adquirido, o hubiera pagado un precio menor, si los hubiera conocido"; en tanto que el artículo 1644 dispone: "En los casos de los artículos 1641 y 1643, el comprador podrá elegir entre devolver la cosa y que le sea restituido el precio, o guardar la cosa y que se le restituya una parte del precio, valorada por peritos". Colin y Capitant comentan, sin embargo, que aunque la doctrina de las acciones estimatoria y redhibitoria coinciden en casi todos los detalles, pues son los mismos elementos personales y los mismos casos en lo que pueden ejercitarse, parece más propio que la acción redhibitoria se ejerza en caso que el comprador de haber conocido el defecto no la hubiera comprado, y la estimatoria si en ese mismo caso igualmente hubiere celebrado la venta, pero dando menos por ella. Aunque debemos resaltar que no explican las razones para sustentar esa opinión. Colin, Ambrosio y CaPITANT, H. (1955): Curso elemental de derecho civil (Madrid, Editorial Reus), T. IV, p. 217.

${ }^{6}$ Así se visualiza en el artículo 1484: "El vendedor estará obligado al saneamiento por los defectos ocultos que tuviere la cosa vendida, si la hacen impropia para el uso a que se la destina, o si disminuyen de tal modo este uso que, de haberlos conocido el comprador, no la habría adquirido o habría dado menos precio por ella; pero no será responsable de los defectos manifiestos o que estuvieren a la vista, ni tampoco de los que no estén, si el comprador es un perito que, por razón de su oficio o profesión, debía fácilmente conocerlos". A su turno, el artículo 1486, inciso primero, dispone: "En los casos de los dos artículos anteriores, el comprador podrá optar entre desistir del contrato, abonándosele los gastos que pagó, o rebajar una cantidad proporcional del precio, a juicio de peritos".
}

7 De Verda y Beamonte, José (2002): “La falta de armonía entre la tipificación del vicio redhibitorio y los remedios jurídicos con que cuenta el comprador de una cosa defectuosa", en: Anuario de derecho civil (fascículo II), p. 642. 
relevancia a cualquier vicio que implique una disminución de la utilidad que el comprador esperare de la cosa ${ }^{8}$.

Bello, en cambio, introdujo dos variaciones al sistema contenido en el Code. De una parte, estableció explícitamente las calidades que debe reunir un vicio para que tenga el carácter de redhibitorio ${ }^{9}$, en cuyo caso el comprador tiene derecho a exigir la rescisión de la venta o la rebaja del precio, según mejor le pareciere, como dispone el artículo 1860; y en seguida, dispuso que en caso de que el vicio no tenga la importancia exigida de conformidad a lo establecido en el artículo $1858^{\circ} 2$, el comprador sólo tendrá derecho al ejercicio de la acción de rebaja de precio conforme al artículo $1868^{10}$, y sin perjuicio de que se permite igualmente el ejercicio de la acción de rebaja del precio en caso que la acción redhibitoria haya prescrito, como establece el artículo 1867. Sobre este aspecto, nos referiremos algunas líneas más adelante.

Debemos hacer un alcance, para efectos de este estudio utilizaremos la denominación de rebaja del precio, reducción del precio o quanti minoris, indistintamente, no sólo a los casos en que se ejerce esta acción ante un vicio que no reviste la gravedad exigida en el artículo 1868, y para la situación en que la acción redhibitoria se encuentre prescrita como se lee en el artículo 1867, sino también para los grupos de casos en que reuniéndose los requisitos establecidos en el artículo 1858 el comprador opta por demandar la rebaja proporcional del precio $^{11}$.

\footnotetext{
${ }^{8}$ De Verda y BeAmonte,, José (2002): "La falta de armonía entre la tipificación del vicio redhibitorio y los remedios jurídicos con que cuenta el comprador de una cosa defectuosa", en: Anuario de derecho civil (fascículo II), pp. 651-656.

9 El texto contenido en el artículo 1858 no sufrió mayores enmiendas desde los primeros proyectos de Código Civil, a excepción de algunas precisiones gramaticales incluidas por Bello, como se visualiza en los proyectos de 1842 y 1847 . Repertorio del Código Civil, artículo 1858.

${ }^{10}$ El artículo 1868 aparece también en el proyecto inédito, pero no hay mayores antecedentes de las fuentes utilizadas por Bello.

11 A diferencia de la postura del profesor Alejandro Guzmán, quien teniendo presente el tenor del artículo 1857, reserva la denominación de "acción redhibitoria" para los casos en que se reúnan los requisitos establecidos en el artículo 1858, y el comprador opte ya por la rescisión, ya por la rebaja del precio. GUZMÁN BRITO, Alejandro (2007): "Sobre la relación entre las acciones de saneamiento de los vicios redhibitorios y las acciones comunes de indemnización, con especial referencia a su prescripción", en: Revista Chilena de Derecho Privado (№ 9, diciembre), p. 97. Y ello, debido a dos razones: primero, porque se trata de la denominación con que se la reconoce cada vez que el comprador solicita una reducción del precio, independiente de las razones que lo han llevado a su ejercicio -mera elección, vicio no grave, o acción de rescisión prescrita-; y en seguida, por cuanto, como hemos señalado, nuestro Código Civil innovó en lo que respecta a conceder esta acción ante vicios menos graves. De modo que en el derecho extranjero la doctrina denomina a la acción mediante la cual se solicita reducción del precio, acción de rebaja de precio, quanti minoris o estimatoria, no obstante se suele permitir su ejercicio, como hemos indicado anteriormente, solo si el vicio es grave, es decir, en las mismas hipótesis en que se permita el ejercicio de la acción tendiente a dejar sin efecto la compraventa.
} 


\subsection{La naturaleza de la acción de rebaja del precio}

Referirnos a la naturaleza de la acción de rebaja del precio en este trabajo tiene una finalidad meramente instrumental, puesto que sus rasgos característicos coadyuvarán a identificar o definir algunos criterios para cuantificar la reducción del precio demandada, por lo que nuestro objetivo no es hacer un análisis profundo sobre este tópico, sino únicamente destacar algunas opiniones de la doctrina.

Una segunda cuestión que conviene aclarar, es que, como se sabe y ya hemos mencionado, la multiplicidad de acciones con que cuenta el comprador no sólo dificulta la decisión de los operadores del derecho respecto de qué acción o acciones serán las más idóneas de ser ejercitadas en un caso particular, sino que ello también oscurece la calificación de las acciones edilicias en el derecho contemporáneo ${ }^{12}$.

Para comprender este punto, recordemos lo que se ha señalado con relación a los diversos sistemas adoptados por los ordenamientos jurídicos acerca del alcance de la obligación del vendedor de entregar la cosa: de una parte hay aquellos en que rige el principio caveat emptor, según el cual el vendedor no garantiza al comprador las cualidades de la cosa, salvo acuerdo en contrario y dolo del vendedor ${ }^{13}$; luego, el propio de las codificaciones decimonónicas en que el vendedor se obliga a entregar la cosa y a sanearla ${ }^{14}$, mas no a entregar

12 Sobre este ámbito en nuestro país, Caprile BiermanN, Bruno (2007): "Las acciones del comprador insatisfecho: el cúmulo actual y la tendencia al deber de conformidad", en: Hernán Corral y María Sara Rodríguez (coords.), Estudios de derecho civil II (Santiago, LexisNexis), pp. 629-650 y FigueroA YÁÑEZ, Gonzalo (2011): "Rescisión, resolución y redhibición: ¿puede hablarse de un 'cúmulo de acciones'?", en: Alex Zúñiga Tejos (coord.), Estudios de derecho privado. Libro homenaje al jurista René Abeliuk Manasevich (Santiago, Editorial Jurídica de Chile), pp. 111-120. Esta problemática, por lo demás, ha sido una preocupación constante también en el derecho extranjero, solo a vía ejemplar, en el derecho español ya se ponía de manifiesto por BerCovitz y Rodrícuez CANO, Rodrigo (1969): "La naturaleza de las acciones redhibitoria y estimatoria en la compraventa", en: Anuario de derecho civil (fascículo IV), p. 777, Morales Moreno, Antonio (1980): "El alcance protector de las acciones edilicias", en: Anuario de derecho civil (fascículo III), p. 590 y Pantaleón Prieto en un trabajo que ha pasado a ser un clásico de la doctrina hispana, PANTAleón PRIETO, Fernando (1993): "Las nuevas bases de la responsabilidad contractual", en: Anuario de derecho civil (fascículo IV), p. 1723. Más recientemente nuevamente en Morales Moreno, Antonio (2006): La modernización del derecho de obligaciones (Madrid, Aranzadi S.A.), p. 25; VAQUer Alor, Antoni (2011): "El principio de conformidad: ¿supraconcepto en el Derecho de obligaciones?, en: Anuario de derecho civil (fascículo I), p. 10. SORTAIs, Jean-Pierre (2008): "El saneamiento en la compraventa de bienes de consumo", en: Revista Chilena de Derecho (Volumen XXXV, No 3), p. 605, entre muchos.

13 Morales Moreno, Antonio (2012): "Tres modelos de vinculación del vendedor en las cualidades de la cosa", en: Anuario de derecho civil (fascículo I), p. 11.

14 AlesSANDri Rodríguez, Arturo (1918): De la compraventa y de la promesa de venta (Santiago, Sociedad Imprenta Litografía Barcelona), tomo segundo, pp. 3-5. Discrepa Bercovitz y Rodrícuez Cano, Rodrigo 
una cosa sin vicios o defectos, lo que se manifiesta en las acciones redhibitoria y estimatoria ${ }^{15}$; y el tercer sistema o modelo, aquel en que el vendedor se obliga a entregar una cosa conforme, esto es a "entregar una cosa con las cualidades que debe tener según el contrato", contenido en la $\mathrm{CISG}^{16}$. Claro está que nuestro sistema adscribe al segundo modelo, por consiguiente, se podría aseverar que el vendedor que entrega una cosa con vicios o defectos no incumple el contrato, sino que surge su obligación de sanearla como se lee del artículo 1824, obligación que luego se detalla en el artículo 1837, ninguna de las cuales fue objeto de mayores modificaciones durante el proceso de elaboración del Código.

No obstante, igualmente se ha presentado la discusión en orden al fundamento que tendrían las acciones edilicias, aspecto en que la doctrina foránea ha sido fecunda y en que, como expone Bercovitz, las opiniones han transitado entre considerarlas acciones fundadas en el error del comprador, y el incumplimiento contractual de parte del vendedor ${ }^{17}$. Se agrega que está involucrada la distribución de riesgos en la compraventa en favor del comprador, de modo que al celebrar el contrato el vendedor asume el riesgo de tener que responder si la cosa tiene vicios ${ }^{18}$. En definitiva, opiniones autorizadas se han inclinado por reconocer que se trata de un particular medio de protección de los intereses del comprador, mediante un mecanismo de responsabilidad especial consagrado

(1969): "La naturaleza de las acciones redhibitoria y estimatoria en la compraventa", en: Anuario de derecho civil (fascículo IV), p. 817, pues considera que "el saneamiento por vicios ocultos no es una segunda obligación del vendedor ni corresponde a otra obligación diversa de la de entrega de la cosa. No es más que la forma de responsabilidad que corresponde a un tipo de incumplimiento de la entrega de la cosa debida". No obstante, el propio artículo 1461 del Código Civil español señala que el vendedor está obligado a la entrega y saneamiento de la cosa objeto de la venta, en términos similares a nuestro artículo 1824, aunque en el nuestro el propio legislador indica que la entrega y el saneamiento son dos obligaciones distintas.

15 Morales Moreno, Antonio (2012): "Tres modelos de vinculación del vendedor en las cualidades de la cosa", en: Anuario de derecho civil (fascículo I), pp. 12-13.

16 Morales Moreno, Antonio (2012): "Tres modelos de vinculación del vendedor en las cualidades de la cosa", en: Anuario de derecho civil (fascículo I), p. 19.

17 Bercovitz y Rodríguez Cano, Rodrigo (1969): "La naturaleza de las acciones redhibitoria y estimatoria en la compraventa", en: Anuario de derecho civil (fascículo IV), pp. 780-799. Sobre las razones por las cuales a las acciones edilicias se le habría explicado en clave de incumplimiento, véase MORALES Moreno, Antonio (1980): "El alcance protector de las acciones edilicias", en: Anuario de derecho civil (fascículo III), pp. 662-663.

18 De Verda y Beamonte, José (2009): Saneamiento por vicios ocultos. Las acciones edilicias (Navarra, Aranzadi Thomson Reuters), p. 293. 
por el ordenamiento jurídico ${ }^{19}$, de ahí que se las suele calificar como acciones de garantía ${ }^{20}$.

La doctrina nacional también ha hecho algunos planteamientos referidos a la naturaleza de las acciones edilicias. Ya Alessandri nos recordaba que los autores franceses discutían si la obligación de sanear que se materializa con el ejercicio de las acciones edilicias es efectivamente una verdadera obligación de saneamiento, o si se trata de una responsabilidad que afecta al vendedor; no obstante, citando a Guillouard y a Ricci considera que el término sanear "se aviene perfectamente con el carácter de los vicios redhibitorios puesto que garantir i sanear significa protejer i tanto en el caso de la evicción como en el de esos vicios, el vendedor debe protejer al comprador en su posesión libre, en el primer caso, i útil, en el segundo" 21 . Alejandro Guzmán, de otra parte, destaca que toda vez que para el ejercicio de las acciones edilicias no se requiere de culpa o dolo del deudor, "la disciplina de estas tres acciones es objetiva, lo cual quiere decir que el vendedor responde si hubo vicios ocultos preexis-

${ }^{19}$ Morales Moreno, Antonio (1980): "El alcance protector de las acciones edilicias", en: Anuario de derecho civil (fascículo III), p. 679.

${ }^{20}$ Con la dictación del Código Civil italiano de 1942, ya se destacaba que tanto la acción redhibitoria como la quanti minoris son acciones de garantía por vicios y por falta de cualidad de la cosa. LuzZATTO, Ruggero (1953): La compraventa según el nuevo código civil italiano (Madrid, Instituto Editorial Reus), p. 269. Similar planteamiento en el derecho alemán, EnNeCCERus, Ludwig (1948): Tratado de derecho civil. Derecho de obligaciones (Buenos Aires, Bosch, Publicaciones Jurídicas), Volumen II, pp. 50-51; Hedemann, J.W. (1958): Derecho de obligaciones (Madrid, Editorial Revista de Derecho Privado), Volumen III, p. 259. Sin perjuicio de ello, en Alemania se presentaban similares problemas respecto a la posible superposición de acciones y a los alcances del vicio que posibilitaba el ejercicio de estas acciones. Empero, luego de la reforma del año 2001 que modernizó el derecho de obligaciones, y que en el caso del contrato de compraventa se vio impactado con la incorporación obligatoria de la Directiva europea sobre bienes de consumo 1999/44/CE, el sistema de acciones o derechos del comprador del $B G B$ sufre un vuelco radical, puesto que toma como modelo el sistema de compraventa de cosa genérica, propio de la CISG, unificando la reglamentación para la compraventa genérica y para la de bienes específicos, y se intenta "integrar la responsabilidad por vicios ocultos, en la medida de lo posible, en el régimen general de la infracción del contrato instaurado por la reforma del derecho alemán de obligaciones que, a su vez, se ha inspirado en los principios del Convenio de Viena". ZimmermanN, Reinhard (2008): El nuevo derecho alemán de obligaciones. Un análisis desde la Historia y el Derecho comparado. (Traducción Esther Arroyo i Amayuelas, Barcelona, Bosch), pp. 109-111. Ehmann, Horst y SutsChet, Holger (2006): La reforma del BGB. Modernización del derecho de alemán de obligaciones. (Traducc. Claudia López Díaz y Ute Salach de Sánchez, Bogotá, Universidad de Externado de Colombia), p. 245. MarkesInIs, Basil, Unberath, Hannes y Johnston, Angus (2006): The German Law of Contract. A Comparative Treatis (Oxford, Hart Publishing), pp. 496-497. Lo anterior, sin perjuicio de lo que se señalará en orden a la forma en que quedó regulada la acción de rebaja de precio.

21 Alessandri RodríGuez, Arturo (1918): De la compraventa y de la promesa de venta (Santiago, Sociedad Imprenta Litografía Barcelona), tomo segundo, pp. 252-253. 
tentes al contrato, aunque no los haya conocido ni tenido que conocer"22; no obstante, más adelante atendidos los cambios de redacción introducidos por Bello al actual artículo 1857, postula que la acción redhibitoria es una acción rescisoria más que resolutoria, puesto que de tener este último carácter, al comprador siempre se le reconocería el derecho a obtener la indemnización del daño emergente y del lucro cesante; en cambio, la acción redhibitoria solo daría lugar a la restitución del precio pagado, efecto más cercano al de la rescisión por aplicación de las reglas de las prestaciones mutuas ${ }^{23}$. En lo que toca a la acción de rebaja de precio, también tendría por función rescindir el contrato -entendemos que parcialmente- y conseguir una acotada indemnización de perjuicios consistente en un monto de daño emergente como sería la reducción de precio. En un reciente trabajo sobre el cumplimiento imperfecto en el contrato de compraventa, el profesor De la Maza postula que las acciones edilicias constituirían un régimen especial de remedios en la compraventa ${ }^{24}$, con "un funcionamiento objetivo", adicionando que en este caso el incumplimiento a que da lugar su ejercicio quedaría incorporado -utiliza la expresión "encapsulado" - en la obligación de saneamiento 25.

Hay que resaltar, que aunque se postule que las acciones edilicias no tienen su fundamento en un incumplimiento del deudor, es evidenciable que la superposición de estas acciones con las del incumplimiento contractual hoy se ve agudizada por dos razones adicionales: la primera, debido a la amplitud con que el derecho contemporáneo configura el incumplimiento contractual, que implica que un defecto ${ }^{26}$ en la cosa vendida sea susceptible de ser incorporado

22 GuZmán Brito, Alejandro (2007): "Sobre la relación entre las acciones de saneamiento de los vicios redhibitorios y las acciones comunes de indemnización, con especial referencia a su prescripción", en: Revista Chilena de Derecho Privado ( $N^{\circ}$ 9, diciembre), p. 98.

${ }^{23}$ Guzmán Brito, Alejandro (2007): "Sobre la relación entre las acciones de saneamiento de los vicios redhibitorios y las acciones comunes de indemnización, con especial referencia a su prescripción", en: Revista Chilena de Derecho Privado (№ 9, diciembre), p. 100.

${ }^{24}$ De la Maza Gazmurı, Íñigo (2012): "El régimen de los cumplimientos defectuosos en la compraventa", en: Revista Chilena de Derecho (Volumen XXLIX, № 3), p. 637.

25 De la Maza Gazmurı, Íñigo y Pizarro Wilson, Carlos (2006): Responsabilidad civil. Casos prácticos (Santiago, LexisNexis), p. 647. Ello, sin perjuicio de la finalidad que persigue la acción indemnizatoria contenida en el artículo 1861, que el autor justifica en la reprochable conducta del vendedor al incumplir un deber precontractual de información, como explica en otro trabajo. De LA MAZA GAZMURI, Íñigo (2011): "La distribución del riesgo y la buena fe. A propósito del error, el dolo y los deberes precontractuales de información", en: Revista de Derecho de la Pontificia Universidad Católica de Valparaíso (XXXVII, $2^{\circ}$ semestre), p. 118.

${ }_{26}$ Morales Moreno, Antonio (1980): "El alcance protector de las acciones edilicias", en: Anuario de derecho civil (fascículo III), p. 630. 
en una noción amplia de incumplimiento ${ }^{27}$, posibilitando al comprador ejercer las acciones pertinentes; $y$ en segundo lugar, atendida la holgura con que se puede interpretar la noción de vicio o defecto en la cosa, que ha permitido -aunque no sin discusiones- integrar nociones tales como vicios subjetivos ${ }^{28} \mathrm{y}$ vicios jurídicos ${ }^{29}$, y muchas veces confundirlos con casos de "aliud pro alio" ${ }^{130}$, facilitando el ejercicio de las acciones edilicias. A ello se agrega que, como resalta la doctrina, las acciones edilicias están concebidas para la compraventa

\footnotetext{
27 Morales Moreno, Antonio (2009): "Problemas que plantea la unificación del concepto de incumplimiento del contrato. Respuesta a Enrique Barros", en: Derecho de daños (Madrid, Fundación Coloquio Jurídico Europeo), p. 207. Morales Moreno, Antonio (2010): Incumplimiento contractual y lucro cesante (Madrid, Civitas), p. 29; VIDAL OlIVARES, Álvaro (2006): "El incumplimiento contractual y los remedios de que dispone el acreedor en la compraventa internacional", en: Revista Chilena de Derecho Nolumen XXXIII, No 3), p. 439. Véase especialmente VIDAl Olivares, Álvaro (2007): "Cumplimiento e incumplimiento contractual en el Código Civil. Una perspectiva más realista", en: Revista Chilena de Derecho (Volumen XXXIV, No 1), pp. 41-59.
}

${ }^{28}$ Así, se ha distinguido entre una noción conceptual, que propugna un concepto de vicio que considera el uso normal que tiene la cosa en el tráfico, v/s un concepto funcional, que postula considerar el concreto uso que el comprador pretende hacer de ella, por esta última se inclina De VERDA y BEAMONTE, José (2009): Saneamiento por vicios ocultos. Las acciones edilicias (Navarra, Aranzadi Thomson Reuters), pp. 25-40. Igual opinión Díez Picazo, Luis y Gullón, Antonio (2005): Sistema de derecho civil. El contrato en general. La relación obligatoria. Contratos en especial. Cuasicontratos. Enriquecimiento sin causa. Responsabilidad extracontractual (Madrid, Editorial Tecnos), p. 281. PANTAleón PRIETo, Fernando (1993): "Las nuevas bases de la responsabilidad contractual", en: Anuario de derecho civil (fascículo IV), p. 1723. Un análisis de contraste entre la jurisprudencia chilena y colombiana sobre el alcance del vicio redhibitorio, en Oviedo Albán, Jorge (2010): "Sobre el concepto de vicio redhibitorio en la compraventa. Análisis comparado de la jurisprudencia chilena y colombiana", en: Revista Chilena de Derecho (vol. 37, № 2), pp. 241-269.

${ }^{29}$ En la jurisprudencia nacional se divisa una posición reacia a aceptar vicios que no tengan un carácter estrictamente material dentro del concepto "vicio oculto". Así, en Abarca Bustamante, Leopoldo con Bruna, Silvia Inés (2003): Corte Suprema, 1 de octubre de 2003 (casación en el fondo), Microjuris № 9369, desecha la calificación de vicio oculto a una expropiación de la que el comprador no tenía conocimiento. Similar en causa Araya Brito, Carlos con Banco Santander (2011): Corte Suprema, 24 de octubre de 2011 (casación en la forma y fondo), vlex 333761494, que rechaza la casación en el fondo de la demandante, puesto que el vicio alegado es no contar el inmueble con la recepción municipal. De igual forma, se niega la configuración de un vicio redhibitorio en sentencia de la Corte Suprema de 26 de septiembre de 2012, pues se alega que se habría comprado un inmueble en que luego terceros alegan tener mejor derecho, causa Toro Mancilla, Rodrigo con Banco Santander de Chile (2011): Corte Suprema, 26 de septiembre de 2011 (casación en el fondo), Poder Judicial.

${ }^{30}$ Bercovitz y Rodríguez CANO, Rodrigo (1969): "La naturaleza de las acciones redhibitoria y estimatoria en la compraventa", en: Anuario de derecho civil (fascículo IV), p. 818. Aunque en España el efecto fundamental ha sido el primero, esto es, que los casos de vicios ocultos o redhibitorios sean conocidos por los tribunales mediante el sistema general de acciones de incumplimiento. Morales Moreno, Antonio (2006): La modernización del derecho de obligaciones (Madrid, Aranzadi S.A.), p 37. Este tipo de inconvenientes llevó a Pantaleón Prieto a proponer que la acción redhibitoria fuere "absorbida" por la resolución por incumplimiento, a la vez que generalizar la acción de reducción del precio. PANTALEÓN PrIETO, Fernando (1993): "Las nuevas bases de la responsabilidad contractual", en: Anuario de derecho civil (fascículo IV), pp. 1723-1724. 
de bienes específicos y no de bienes genéricos, lo que constituiría una deficiencia en este sistema de acciones, pues no estaría acorde a las necesidades del tráfico contemporáneo, a diferencia de la CISG que razona sobre la base de un contrato sobre bienes genéricos ${ }^{31}$.

Todo ello, ha generado como consecuencia el planteamiento de algunos en orden a sustituir la noción de saneamiento por la de "falta de conformidad", al modo de la misma $\mathrm{CISG}^{32}$, como se plantea en la Propuesta de modernización del derecho de las obligaciones y contratos español ${ }^{33}$.

Corresponde ahora mirar con mayor detenimiento a la acción de rebaja proporcional de precio o quanti minoris, puesto que aunque se califique a las acciones edilicias como acciones de garantía ${ }^{34}$, cuyo fundamento se explican en la necesidad de distribuir los riesgos de la cosa comprada, interesa considerar las particularidades que presenta este derecho del comprador, por dos órdenes de razones: la primera, porque a diferencia de la acción redhibitoria, en este caso el contrato permanece vigente; y en seguida, por cuanto, a pesar de las críticas y deficiencias que puede presentar el modelo de acciones edilicias, resulta, que contrariamente a lo que ocurre con la acción redhibitoria -sobre la que se plantea su eliminación-, como ya hemos comentado, se denota la tendencia por mantener, y aun por generalizar, a la acción de rebaja proporcional del precio ${ }^{35}$.

31 ZimmermanN, Reinhard (2008): El nuevo derecho alemán de obligaciones. Un análisis desde la Historia y el Derecho comparado (traducción Esther Arroyo i Amayuelas, Barcelona, Bosch), p. 97. Sobre el alcance de la obligación de entregar la cosa sin vicios, en que se destaca la diferencia entre la compraventa de cosa genérica y la compraventa de cosa específica, y la eventual inaplicabilidad de las acciones edilicias a la primera, véase De Verda y BeAmOnTE, José (2009): Saneamiento por vicios ocultos. Las acciones edilicias (Navarra, Aranzadi Thomson Reuters), pp. 268-281.

32 Ello permitiría unificar bajo ese concepto cualquier "desviación de los bienes respecto de las expectativas del comprador". VAQUER Alor, Antoni (2011): "El principio de conformidad: ¿supraconcepto en el Derecho de obligaciones?, en: Anuario de derecho civil (fascículo I), p. 11.

33 Fenor Picón, Nieves (2010): "La Modernización del régimen del incumplimiento de contrato: Propuestas de la Comisión General de Codificación. Parte segunda: los remedios del incumplimiento", en: Anuario de Derecho civil (fascículo IV), p. 65; VIDAL Olivares, Álvaro (2011): "El incumplimiento y los remedios del acreedor en la Propuesta de Modernización del derecho de las obligaciones y contratos español", en: Revista Chilena de Derecho Privado (№ 16), p. 265. García Pérez, Rosa (2011): "Construcción del incumplimiento en la Propuesta de Modernización: la influencia del Derecho privado europeo", en: Klaus Albiez (dir.), Derecho privado europeo y modernización del Derecho contractual en España (Barcelona, Atelier Libros Jurídicos), pp. 337-345.

34 Barros Bourie (2006) (a), Tratado de responsabilidad extracontractual (Santiago, Editorial Jurídica de Chile), p. 983.

35 En los procesos de modernización de derecho de obligaciones y contratos, hay una idea de generalización en el "Proyecto Terré" de modificación al Code, Pizarro Wilson, Carlos (2011): "Los remedios al incumplimiento contractual en los proyectos franceses de reforma al Derecho de Contratos", en: Revista de Derecho de la Pontificia Universidad Católica de Valparaíso (XXXVI, $1^{\circ}$ semestre), pp. 130131; pero se aprecia en forma más clara en la Propuesta española para la Modernización del derecho 
La conservación del contrato, pero con una readecuación prestacional, son, sin duda, los rasgos característicos de la acción quanti minoris, que posibilitan determinar su naturaleza y fundamento. Así, se ha señalado que la acción de rebaja de precio tiene por finalidad mantener el sinalagma y equilibrio de las prestaciones, permitiendo al comprador imponer una modificación unilateral del contrato ${ }^{36}$. Por su parte, Morales Moreno resalta que el vendedor se vincula a satisfacer un interés negativo del deudor, que en el caso de la acción quanti minori, supone "reconfigurar la equivalencia subjetiva del contrato, contando con el verdadero estado de la cosa" ${ }^{\prime 3}$.

Sin embargo, debemos reconocer que también sería posible conferir a la acción de rebaja proporcional del precio una naturaleza indemnizatoria, en un doble sentido: primero, integrando el monto en que el precio de la cosa se reduce en la indemnización de perjuicios, si se estima que el comprador, además de las acciones edilicias, podría optar por ejercer las acciones derivadas de cualquier incumplimiento contractual; y en un segundo sentido, calificar a esta acción como una acción indemnizatoria especialísima, propia de la compraventa $-y$ del contrato de arrendamiento, cuando procede- ${ }^{38}$, y distinta, además, de la

de obligaciones y contratos, artículos 1197 y 1198. El artículo 1197 establece: "La parte que hubiere recibido una prestación no conforme con el contrato, podrá aceptarla y reducir el precio en proporción a la diferencia entre el valor que la prestación tenía en el momento en que se realizó y el que habría tenido en ese mismo momento si hubiera sido conforme con el contrato.

La parte que tenga derecho a reducir el precio y que haya pagado una suma mayor, tendrá derecho a reclamar el reembolso del exceso.

El ejercicio de las facultades previstas en este artículo caducará a los seis meses a partir del momento en que hubiera recibido la prestación".

36 De Verda y Beamonte, José (2009): Saneamiento por vicios ocultos. Las acciones edilicias (Navarra, Aranzadi Thomson Reuters), p. 264. También lo ve como una imposición de una modificación contractual a la otra parte, Bercovitz y Rodrícuez Cano, Rodrigo (1969): "La naturaleza de las acciones redhibitoria y estimatoria en la compraventa", en: Anuario de derecho civil (fascículo IV), p. 789.

37 Morales Moreno, Antonio (2012): "Tres modelos de vinculación del vendedor en las cualidades de la cosa", en: Anuario de derecho civil (fascículo I), p. 16. A la idea de equilibrio del contrato también recurre Fenoy en su comentario sobre la Propuesta de modernización española de 2009. Fenor Picón, Nieves (2011): "La Modernización del régimen del incumplimiento de contrato: Propuestas de la Comisión General de Codificación. Parte primera: Aspectos generales. El incumplimiento", en: Anuario de derecho civil (fascículo I), p. 1562. De similar opinión, VIDAL Olivares, Álvaro (2011): "El incumplimiento y los remedios del acreedor en la Propuesta de Modernización del derecho de las obligaciones y contratos español", en: Revista Chilena de Derecho Privado (No 16), p. 281.

${ }^{38}$ En el contrato de arrendamiento, el sistema del Código Civil chileno es relativamente similar en los casos en que procede la rebaja de la renta y la indemnización de perjuicios. Así, en el artículo 1928 el arrendatario puede solicitar la rebaja de la renta en caso que deban efectuarse reparaciones en la cosa que no puedan diferirse, y si dichas reparaciones procedieren de causa que existía al tiempo del contrato y no eran conocidas por el arrendatario, pero lo eran por el arrendador, o tales que el arrendador tuviese antecedentes de tenerla, o debiese por su profesión conocerla, también tiene derecho 
acción indemnizatoria que el comprador puede ejercer conforme al artículo 1861 del Código Civil chileno. Una interpretación semejante, empero, genera como efecto la pérdida de autonomía de la acción de rebaja proporcional del precio, además de desaprovechar su potencialidad y relevancia de convertirse en una acción o remedio de aplicación general. Es más, la calificación de acción resarcitoria ha sido uno de los antecedentes que se han considerado por un sector de la doctrina que aboga por su abolición ${ }^{39}$.

Si bien en el derecho nacional no hay mayor desarrollo sobre la específica naturaleza de la acción de rebaja proporcional del precio, podemos apreciar que nuestra jurisprudencia tiende a calificarla de acción indemnizatoria, indicando que la acción de rebaja de precio integraría la indemnizatoria ${ }^{40}$, posición

a indemnización de perjuicios. Por su parte, el artículo 1932 dispone la rebaja de la renta para el caso en que el mal estado o calidad de la cosa solo permite al arrendatario un goce parcial de ella, o si la cosa se destruye en parte; a la vez, el artículo 1933 establece que el arrendatario tiene derecho a la indemnización del daño emergente si el vicio de la cosa ha tenido causa anterior al contrato; si el vicio era conocido del arrendador a tiempo del contrato o si era tal que el arrendador debiera por los antecedentes preverlo o por su profesión conocerlo, se incluye el resarcimiento del lucro cesante.

39 FerRante, Alfredo (2012): La reducción del precio en la compraventa (Navarra, Thomson Reuters, Aranzadi), pp. 81-82. Otro de los argumentos que se han esbozado, recuerda Ferrante, para propugnar la eliminación de la acción, es que atendida la influencia que ha tenido el common law en el derecho continental de obligaciones y contratos, la acción de indemnización de perjuicios es el derecho primordial del acreedor, agregándose que la reducción del precio es más bien extraña en dicho sistema. Sobre ello, véase también PILIOUNIS, Peter A. (2000): "The remedies of specific performance, Price reduction and additional time (Nachfrist) under the CISG: are these worthwhile chances or additions to english law?", en: Pace international law review (Volumen XII), p. 37. Disponible en: http://digitalcommons. pace/edu/pilr/vil12/iss1/2. [visitado el 01/04/2014].

40 Así, en causa Servicios de impresión J.A. Amenábar Ltda. con Fuentes Riquelme, Iván (2008): Corte Suprema, 4 de agosto de 2008 (casación en el fondo), Microjuris № 17851. En este caso, se ejerció acción de rebaja de precio e indemnización de perjuicios, fundadas en el incumplimiento de un contrato de arrendamiento-leasing de una máquina de impresión usada. La máquina fue probada antes de la compra y mostraba algunos problemas en los traspasos de los pliegos de papel, pero el demandado indicó que bastaba llevar a cabo un pequeño ajuste para solucionarlo, sin embargo, una vez celebrada la compra e instalada, la máquina no funcionó de la forma esperada, haciéndola inútil para los fines que fue adquirida; se alega, además, que se trata de vicios conocidos por el demandado. La demandada, por su parte, centró su principal defensa en que la acción quanti minoris estaría prescrita, por lo que también lo estaría la acción indemnizatoria. Tanto la sentencia de primera como de segunda instancia, acogieron la excepción de prescripción de ambas acciones. La Corte Suprema, conociendo del recurso de casación en el fondo deducido por la actora, invalidó de oficio la sentencia recurrida, y en la sentencia de reemplazo argumenta que la acción indemnizatoria es independiente, pues no hay razón alguna que permita vincularla en forma determinante ni con la acción redhibitoria, ni con la acción quanti minoris, por lo que pese a estar prescrita esta última, acoge la de indemnización de perjuicios. Pese a concordar con la decisión final, en lo que nos interesa, la Corte asume que la acción de rebaja proporcional del precio tiene naturaleza indemnizatoria, como se lee en el considerando tercero de la sentencia de reemplazo: "Una interpretación armónica e integral de tales disposiciones lleva a entender que la acción resolutoria es la propiamente redhibitoria y la rebaja del precio (quanti minoris o aestimatoria) integra la indemnizatoria, pues en última instancia (declarado el derecho) signi- 
que no compartimos ${ }^{41}$. En efecto, la acción de rebaja proporcional del precio o quanti minoris no tiene una naturaleza indemnizatoria, sino que se trata de una acción de garantía que busca restablecer el equilibrio y conmutatividad de la relación contractual, como ha sido reconocido por la doctrina contemporánea ${ }^{42}$. En ese orden, se trata de una acción que se sustenta en fundamentos diversos, lo que justifica su mantención, e incluso su generalización. La acción de rebaja de precio permite al comprador -o arrendatario- obtener la restitución del precio pagado en exceso, o la reducción del precio que adeuda, sin necesidad de demostrar los requerimientos de la acción de indemnización, entre ellos, la culpa ${ }^{43}$, lo que posibilita que se transforme en una herramienta eficaz en su funcionamiento ${ }^{44}$, a más de ser compatible con la acción de indemnización de

fica que, aplicando el modo de extinguir las obligaciones denominado compensación, podrá importar una rebaja del precio, pero su objeto no queda limitado únicamente a dicha forma de indemnización". Un idéntico razonamiento se encuentra en el considerando undécimo de la sentencia de reemplazo, causa A.G.F. Allianz Chile Compañía de Seguros Generales S.A. con Le Torneau inc. (2010): Corte Suprema, 10 de julio de 2010 (casación en el fondo), Microjuris $N^{\circ}$ 24291; cabe observar que en esta sentencia también se reconoce plena autonomía a la acción indemnizatoria. Por su parte, en causa Larzabal, Beraza Rosario con Sociedad inmobiliaria Talasia Limitada (2008): Corte Suprema, 27 de marzo de 2008 (casación en el fondo), vlex № 332708178, la Corte Suprema expresa en el considerando noveno: "Del mismo modo, siendo desconocidos los vicios para el vendedor, la reparación ha sido limitada a la restitución de lo entregado o la rebaja del precio".

${ }^{41}$ La jurisprudencia española, por el contrario, hace tiempo que reconoce que la acción de rebaja de precio no tiene naturaleza indemnizatoria, sino que tiene como propósito el "restablecimiento de la equidad contractual, como se lee en STS (español) 25 de septiembre 2003 (recurso de casación), Id Cendoj 28079110012003102726.

42 FerRante, Alfredo (2012): La reducción del precio en la compraventa (Navarra, Thomson Reuters, Aranzadi), pp. 86-87.

${ }^{43} \mathrm{Y}$ es que aunque es posible apreciar una tendencia a objetivar la responsabilidad contractual, igualmente el elemento de la culpa constituye aún un elemento distintivo de la pretensión indemnizatoria. BARROS (2006) (b), "La diferencia entre 'estar obligado' y 'ser responsable' en el derecho de los contratos", en: Hernán Corral y María Sara Rodríguez (coords.), Estudios de derecho civil II (Santiago, LexisNexis), p. 724. Sobre la objetivización de la responsabilidad contractual en nuestro derecho véase BARAONA GONZÁlEz, Jorge (1997): "Responsabilidad contractual y factores de imputación de daños: apuntes para una relectura en clave objetiva", en: Revista Chilena de Derecho (Volumen XXIV, No 1), pp. 151-177, De la Maza Gazmuri, Íñigo y Pizarro Wilson, Carlos (2006): Responsabilidad civil. Casos prácticos (Santiago, LexisNexis), pp. 94-111, Peñallillo Arévalo, Daniel (2009): "Responsabilidad contractual objetiva", en: Carlos Pizarro (coord.), Estudios de derecho civil IV (Santiago, LegalPublishing), pp. 331-346.

${ }^{44}$ Por ello, es que se ha sugerido que dicha eficacia se denota también en fase no contenciosa, en que se puede conceder la reducción a la parte interesada. FERRANTE, Alfredo (2011): "Nuevas tendencias en la cuantificación de la reducción del precio", en: Revista para el análisis del derecho (Volumen IV), p. 4; FeRrAnte, Alfredo (2012): La reducción del precio en la compraventa (Navarra, Thomson Reuters, Aranzadi), p. 86. Por su parte, Fenoy es de la opinión que atendida la forma en que se encuentran redactados los párrafos I y III del artículo 1197 de la Propuesta española para la Modernización del derecho de obligaciones y contratos, en particular la utilización de las expresiones "podrá aceptarla y reducir" y "facultades", antes transcrito, permiten inferir que la reducción o rebaja del precio podría ejercitarse 
perjuicios que la parte podría ejercer si ha padecido daños distintos de aquel que supone recibir una cosa con vicio. Tal pretensión indemnizatoria, por cierto, debiese excluir como ítem el menor valor de la cosa, pues sobre éste versa el ejercicio de la acción de reducción proporcional del precio ${ }^{45}$.

\section{Sistemas de cálculo contenidos en los ordenamientos jurídicos}

Considerando las distintas legislaciones extranjeras y el derecho uniforme, es posible sugerir una agrupación sobre la forma de proceder a la hora de rebajar o reducir el precio. Así, un primer grupo es de aquellos ordenamientos que, no obstante reconocen a la acción, no contemplan un sistema para efectos de proceder a la rebaja que se pretende; en segundo lugar, aquellos sistemas que expresamente refieren al cálculo de expertos o peritos, y finalmente, aquellos que establecen un método de cálculo matemático. Se constata que en las legislaciones más recientes, especialmente europeas, se denota alguna tendencia en orden a incorporar un sistema de carácter aritmético, similar se aprecia en el derecho uniforme.

\subsection{Ordenamientos que no consideran en forma expresa la forma de proceder en la rebaja del precio}

Entre estos sistemas jurídicos debemos destacar el italiano, que consagra la acción de reducción del precio en el contrato de compraventa, pero no establece ninguna indicación o parámetro que permita proceder a la misma, como queda de manifiesto en el artículo 1492. Algo similar se aprecia en la regulación del contrato de arrendamiento ${ }^{46}$. Por consiguiente, como se ha

extrajudicialmente. FENOY PICÓN, Nieves (2011): "La Modernización del régimen del incumplimiento de contrato: Propuestas de la Comisión General de Codificación. Parte primera: Aspectos generales. El incumplimiento", en: Anuario de derecho civil (fascículo I), p. 1563. De similar opinión Vidal, en caso que aún no se haya pagado el precio. Vidal Olivares, Álvaro (2011): "El incumplimiento y los remedios del acreedor en la Propuesta de Modernización del derecho de las obligaciones y contratos español", en: Revista Chilena de Derecho Privado (№ 16), p. 282.

45 Así aparece en la Propuesta española para la Modernización del derecho de obligaciones y contratos, artículo 1198: "La parte que ejercite el derecho a la reducción del precio, no puede demandar daños y perjuicios por disminución del valor de la prestación, pero conserva su derecho a ser indemnizado de cualquier otro perjuicios que haya podido sufrir". Así también está previsto en los artículos 9:401 (3) de los PECL y III.3:601(3) del Draf Common Frame of Reference.

${ }^{46}$ Artículo 1492: "Effetti della garanzia. Nei indicati dall’art. 1490 il compratore puo domandare a sua cselta la risoluzione del contratto (1493 e seguenti) overo la riduzione del prezzo, salvo, che, per determinati vizi, gli usi escludano la risoluzione". Artículo 1578: "Se al momento della consegna la cosa locata e affetta da vizi che ne disminuiscono in modo apprezzabile l'idoneita all"uso pattuino, il conduttore puo domandare la risoluzione del contratto o una riduzione del corrispetivo, salvo che si tratti di vizi da lui conosciuti o facilmente riconocibili". 
destacado, el Código Civil italiano de 1942 se limita a repetir lo que ya había sido acogido por el Código Civil de $1865^{47}$. No obstante, la jurisprudencia ha recurrido al artículo 1226, sobre indemnización de perjuicios, para determinar la cuantificación de la rebaja del precio ${ }^{48}$, que ordena al juez a llevar a cabo una avaluación equitativa ${ }^{49}$. El Código suizo de obligaciones, por su parte, regula la venta de una cosa con vicios materiales o legales, en cuyo caso el comprador puede solicitar la rescisión del contrato, o la reducción del precio como forma de compensar el menor valor de la cosa, a menos que el menor valor sea equivalente al precio de la venta, pues el comprador solo podrá rescindir el contrato; si el objeto de la venta recae sobre cosas fungibles, el comprador, además, podrá optar por la sustitución de las mismas, atendido lo dispuesto en los artículos 197, 205 y $206^{50}$.

En el derecho latinoamericano, evidentemente que el Código Civil colombiano tampoco consigna un método de cálculo en la acción de rebaja proporcional del precio a propósito de la compraventa, como tampoco para los casos en que está prevista en el contrato de arrendamiento ${ }^{51}$. Y en códigos latinoamericanos recientes, aunque es posible visualizar un campo de aplicación más vasto a la acción de rebaja del precio, tampoco se contempla una forma de proceder en la misma. Ello ocurre en el Código Civil peruano de 1984, aunque proporciona dos parámetros a considerar en la reducción: el menor valor del bien debido al vicio en el momento de ejercerse la acción de pago y la finalidad de su adqui-

47 Luzzatto, Ruggero (1953): La compraventa según el nuevo Código Civil italiano (Madrid, Instituto Editorial Reus), p. 286.

${ }^{48}$ En efecto, el artículo 1226 dispone: "Valutazione equitativa del danno. Se il danno non puo essere provato nel suo preciso ammontare, e liquidato dal giudice con valuazione equitativa (2056 e seguenti)".

49 FERRANTE, Alfredo (2012): La reducción del precio en la compraventa (Navarra, Thomson Reuters, Aranzadi), p. 136.

${ }^{50}$ Art. 2051 Dans les cas de garantie en raison des défauts de la chose, l'acheteur a le choix ou de faire résilier la vente en exerçant l'action rédhibitoire, ou de réclamer par l'action en réduction de prix une indemnité pour la moins-value.

2 Lorsque l'acheteur a intenté l'action rédhibitoire, le juge peut se bor-ner à réduire le prix s'il estime que la résiliation n'est pas justifiée par les circonstances.

3 Si la moins-value est égale au prix de vente, l'acheteur ne peut demander que la résiliation.

${ }^{51}$ Véase artículos 1914, 1917 y 1925 en la compraventa y 1988 inciso segundo y 1990 inciso segundo, en el arrendamiento de cosas. En el Código Civil argentino, se contempla el saneamiento de vicios redhibitorios para todo contrato en que se transfiera el dominio, uso o goce a título oneroso en el artículo 2164. A la vez, la acción de rebaja de precio se aplica en consideración a la desvalorización que ha experimentado la cosa como consecuencia del vicio, conforme al artículo 2174. Véase PizArRo WILSON, Carlos (coordinador) (2012): El derecho de los contratos en Latinoamérica. (Santiago, Fundación Fernando Fueyo Laneri). Informe Argentina, p. 88. 
sición ${ }^{52}$, y en el reciente Código Civil de Brasil, que también guarda silencio sobre este aspecto ${ }^{53-54}$.

\subsection{Ordenamientos que recurren al juicio de expertos para proceder a la rebaja del precio}

Como ya hemos señalado, el derecho francés permite al comprador elegir entre devolver la cosa y que le sea restituido el precio, o guardar la cosa y que se le restituya una parte de dicho precio, la que será valorada por peritos de acuerdo al artículo 1644. Llama la atención que, a diferencia de nuestro Código, el Code no haga alusión a la proporcionalidad en la determinación del monto a que el precio será reducido, a diferencia de las normas contenidas en el arrendamiento ${ }^{55}$. En lo que toca a la forma en que se procederá a la reducción del precio en la compraventa, los autores suelen dejar ese aspecto precisamente al rol de los expertos ${ }^{56}$. En tanto, en lo que refiere al contrato de arrendamiento

\footnotetext{
${ }^{52}$ Artículo 1513. Acción estimatoria. "El adquirente puede optar por pedir que se le pague lo que el bien vale de menos, por razón de vicio, en el momento de ejercerse la acción de pago, teniendo en cuenta la finalidad de su adquisición, sin perjuicio del derecho que contempla el artículo 1512, inciso $5^{\circ \prime}$. Por su parte, el Código Civil de Paraguay de 1985 tampoco contempla un método aplicable a la rebaja, como se denota de los artículos 1794 y 1795 c), aunque en ambas disposiciones se alude a la reducción del menor valor de la cosa debido al vicio. Cabe destacar, que en este Código se prevé una regulación a los vicios redhibitorios aplicable a los actos en que se transfiere el dominio, uso o goce de una cosa a título oneroso, pero la rebaja del precio sólo procedería en el contrato de compraventa, según se colige de las dos disposiciones antes citadas.
}

${ }^{53}$ Art. 442. "Em vez de rejeitar a coisa, redibindo o contrato (art. 441), pode o adquirente reclamar abatimento no preço". En este caso, se encuentra prevista la acción de reducción del precio para todo contrato conmutativo.

${ }^{54}$ El modelo adoptado por el Código Europeo de contratos adscribe a este grupo de sistemas, pues el artículo 113 dispone: "1. El acreedor que se propone aceptar la entrega de una cosa diferente de valor inferior, o con imperfecciones, o una cantidad de cosas inferiores a la debida, o una prestación de hacer diferente a la pactada o con imperfecciones, tiene el derecho, mediante tempestiva comunicación al deudor, de realizar una contraprestación inferior a lo convenido, haciéndose restituir, eventualmente, parte de lo entregado, en la medida fijada, en defecto de acuerdo, por el juez".

55 No obstante, igualmente la doctrina francesa acude al criterio de la proporcionalidad en el contrato de compraventa. Así, Colin, Ambrosio y CAPITANt, H. (1955): Curso elemental de derecho civil (Madrid, Editorial Reus), T.IV, p. 217; FERRANTE, Alfredo (2012): La reducción del precio en la compraventa (Navarra, Thomson Reuters, Aranzadi), p. 142.

56 Llama la atención la opinión de Baudry-Lacantinerie y Saignat, quienes al analizar en forma somera la manera en que se debería proceder a la reducción del precio en la acción estimatoria, señalan que el juicio de expertos procederá siempre, a menos que las partes hayan llegado a un acuerdo sobre el monto de la rebaja; en caso contrario, señalan que el monto de la rebaja dependerá de si el vendedor conocía o ignoraba los vicios. Si los conocía, el vendedor deberá restituir una suma mayor que si no los conocía. Claramente hay una confusión entre la acción estimatoria y la indemnizatoria, que en el caso del Code se encuentra consagrada en el artículo 1645. Baudry-Lacantinerie, G. y Saignat, Léo 
el artículo 1722 establece que si la cosa arrendada se destruye en parte, el arrendatario podrá, según las circunstancias, pedir una disminución del precio o la rescisión del arrendamiento; por su parte, según el artículo 1724 si la cosa arrendada necesita reparaciones urgentes cuya duración sea superior a cuarenta días, el precio del arrendamiento será disminuido proporcionalmente al tiempo de duración de las mismas, y a la parte de la cosa arrendada de que hubiera sido privado; finalmente, si el arrendatario ha visto perturbado su disfrute a consecuencia de una acción que afecta a la propiedad del predio, también tiene derecho a una disminución proporcional sobre el precio del arrendamiento, ello conforme al artículo 1726. Cabe observar, empero, que nada se dice en el arrendamiento sobre una cuantificación pericial, sin perjuicio de la posibilidad del juez de recurrir al peritaje conforme las normas contenidas en el Code de procédure civile ${ }^{57}$.

El derecho español también recurre al peritaje para cuantificar la reducción del precio en la compraventa, como establece el artículo 1486, según el cual el comprador podrá optar entre desistir del contrato, o rebajar una cantidad proporcional del precio a juicio de peritos. Sobre el método que se encuentra establecido en esta normativa, nos interesa resaltar dos aspectos: el primero dice relación con los parámetros que son susceptibles de ser utilizados en la rebaja; y en segundo término, el rol del peritaje.

Primeramente, cabe resaltar que aunque no se ha establecido de forma específica criterios para proceder a la rebaja del precio, tanto la doctrina como la jurisprudencia han sugerido ciertos parámetros a considerar, algunos de ellos bastante discutibles, como el valor que tendría la cosa sin el vicio, ya sea considerando que la calificación del vicio es objetiva o atendiendo al especial propósito que perseguía el comprador de ella ${ }^{58}$; el monto de los perjuicios padecidos por el comprador debido al defecto de la $\cos ^{59}$, lo que supone confundir

(1900): Droit civil. De la vente et de l'échange (París, Librairie de la Société du Recueil G des Lois et des Arréts), p. 1900.

${ }^{57}$ Article 232 En savoir plus sur cet article. Le juge peut commettre toute personne de son choix pour l'éclairer par des constatations, par une consultation ou par une expertise sur une question de fait qui requiert les lumières $d^{\prime}$ 'un technicien.

${ }^{58}$ Así, se ha señalado que la reducción debería hacerse "no comparando el precio de la cosa viciada con el que tendría objetivamente estando sana, sino con el contractual o pagado. Mas si en el contrato se previó un destino especial (no normal) de la cosa, la disminución de valor se cancelará (para ese solo caso) respecto del que tenga en función de ese uso y no del normal". LaCruz Berdejo, José Luis; Sancho Rebullida, Francisco de Asís, luna Serren, Agustín, Delgado Echeverría, Jesús, Rivero Hernández, Francisco y Rams, Joaquín (2002): Elementos de derecho civil. Derecho de obligaciones. Contratos y cuasicontratos. Delitos y cuasidelitos (Madrid, Dykinson), p. 49.

${ }^{59}$ Véase Puig Peña, Federico (1951): Tratado de derecho civil español (Madrid, Editorial Revista de Derecho Privado) T. IV, Volumen II, p. 126. 
esta acción con la resarcitoria; el monto de las reparaciones necesarias para que la cosa sea idónea ${ }^{60}$, entre otras. En la doctrina española más reciente, se ha propuesto un sistema de cálculo considerando dos elementos para proceder a la reducción: el precio de compra y la disminución proporcional que el defecto produce sobre el bien, este último valor debe ser determinado considerando la disminución funcional del bien y no su valor económico, por ello, es que en esta cuantificación necesariamente se requiere de un dictamen pericial ${ }^{61}$.

A su turno, en lo que refiere al rol del peritaje, las opiniones fluctúan entre aquellos que estiman que para proceder a la rebaja del precio el peritaje es un requisito esencial haciendo prevalecer el artículo 1486 del Código Civil español, por sobre las normas procesales ${ }^{62}$; y quienes consideran que, atendido a lo dispuesto en el artículo 348 de la Ley de Enjuiciamiento española, el juez es soberano para asignarle el valor probatorio que estime conveniente atendidas las reglas de la sana crítica ${ }^{63}$. En todo caso, hay que precisar que el artículo 122 del Texto refundido de la Ley General para la defensa de consumidores y usuarios, establece un mecanismo concreto de cálculo para la rebaja, la que será proporcional a la diferencia existente entre el valor que el producto hubiera tenido al momento de la entrega de haber sido conforme al contrato, y el valor que el producto efectivamente entregado tenía al momento de dicha entrega.

\subsection{Sistemas que consagran una fórmula de cálculo en la rebaja del precio}

El $B G B$ contempla la acción de rebaja del precio para los contratos de compraventa, arrendamiento y contrato de obra, de modo que no obstante la reciente modificación introducida, no se estableció la acción de reducción de precio como remedio de aplicación general. Tanto en el contrato de compraventa, como en el de confección de obra, se establece un método de cuantificación de dicha reducción, a diferencia del contrato de arrendamiento de cosa que solo refiere a que en caso de vicios materiales y jurídicos de la cosa el arrendatario

\footnotetext{
${ }^{60}$ A vía ejemplar, sentencia № 413/2005: Audiencia Provincial de Alicante (apelación), vlex 52202718. En este caso se demanda en lo principal la rebaja del precio, atendido que el inmueble objeto del contrato de compraventa tenía una serie de filtraciones de agua originadas por la corrosión de las cañerías ocultas en la pared cercana al termo de agua, por lo que solicita una suma equivalente a la reparación, lo que se acoge.

${ }^{61}$ FerRANTE, Alfredo (2012): La reducción del precio en la compraventa (Navarra, Thomson Reuters, Aranzadi), pp. 274-275.

62 FerRante, Alfredo (2012): La reducción del precio en la compraventa (Navarra, Thomson Reuters, Aranzadi), p. 166.

${ }^{63}$ Esta postura se ha sostenido por la judicatura, como se aprecia, por ejemplo, en STS (español) 18 de marzo 2004 (recurso de casación), Id Cendoj 28079110012004100182; y en sentencia № 76/2006: Audiencia Provincial de La Rioja (apelación), vlex 285747351.
} 
deberá pagar una renta adecuada ${ }^{64}$. Distinto, decíamos, en la compraventa y en el contrato de obra, pues en ambos casos se establece en forma explícita la forma de proceder a la reducción del precio, aunque luego permite recurrir a la tasación de peritos si fuere necesario ${ }^{65}$.

Sobre la forma de cálculo, el $B G B$ proporciona una fórmula matemática, que implica multiplicar el valor actual de la cosa, por el precio acordado y dividirlo por el valor que la cosa habría tenido de no ser defectuosa ${ }^{66}$. Con todo, en caso de duda la reducción debe ser tasada, como ordena el apartado

${ }^{64}$ El § 536 establece: "(1) Si la cosa arrendada, en el momento de la entrega al arrendatario, tiene un vicio que la hace inidónea para el uso conforme a contrato o si surge un vicio tal durante el plazo de duración del arrendamiento, el arrendatario queda liberado del pago de la renta durante el período en que deviene inidónea. Durante el período en que la idoneidad queda disminuida, éste debe pagar solamente una renta adecuadamente reducida. Una disminución insignificante de la idoneidad no se toma en consideración.

(2) El apartado I, incisos $1^{\circ}$ y $2^{\circ}$, también rigen si falta alguna cualidad garantizada o desaparece con posterioridad.

(3) Si el arrendatario es privado total o parcialmente del uso conforme a contrato de la cosa arrendada por el derecho de un tercero, los apartados 1 y 2 rigen por analogía.

(4) Para una relación arrendaticia sobre una vivienda es ineficaz un acuerdo divergente en perjuicio del arrendatario". Sobre las particularidades en la rebaja del arrendamiento, véase MARKESINIS, Basil, Unberath, Hannes y Johnston, Angus (2006): The German Law of Contract. A Comparative Treatis (Oxford, Hart Publishing), p. 539.

${ }^{65}$ Así, el § 441 en sede de compraventa, dispone: “(1) En lugar de resolver, el comprador puede reducir el precio mediante declaración al vendedor. La causa de exclusión del $\$ 323$, apartado 5, inciso $2^{\circ}$, no es aplicable.

(2) Si existe una pluralidad de sujetos en la parte compradora o vendedora, la reducción sólo puede declararse por todos o frente a todos.

(3) Con la reducción, debe establecerse el precio en proporción al valor que hubiera tenido la cosa estado libre de vicios al tiempo de la celebración del contrato con el valor real. La reducción debe determinarse, si es necesario, mediante tasación.

(4) Si el comprador ha pagado más del precio de compra reducido, el vendedor debe reembolsarle el sobreprecio. El § 346, apartado 1 y el § 347, apartado 1, se aplican por analogía".

Por su parte, en lo que nos interesa, el § 638 sobre contrato de confección de obra, dispone: "(3) Con la reducción debe establecerse la remuneración en proporción al valor que la obra libre de vicios habría tenido al tiempo de la conclusión del contrato y con el valor real. Si es necesario, la reducción debe determinarse mediante tasación".

${ }^{66}$ Markesinis, Basil, Unberath, Hannes y Johnston, Angus (2006): The German Law of Contract. A Comparative Treatis (Oxford, Hart Publishing), p. 510. Los autores dan el siguiente ejemplo: el comprador de un automóvil que tendría un valor de $€ 15.000$, paga un precio al vendedor de $€ 10.000$, y por el defecto que el automóvil presenta tiene un valor de €12.000, la reducción del precio debería ser de $€ 2000$, quedando a un precio reducido de $€ 8.000$. Esto es: $12.000 \times 10.000=120.000 .000 / 15.000=$ 8.000. Precio disminuido $=10.000-2.000=8.000$. Sobre la rebaja en el contrato de confección de obra, los autores resaltan que debe seguirse igual procedimiento que en la compraventa, p. 526. 
3 , del $\S 441^{67}$. Luego de la reforma al derecho de obligaciones del año 2001, el comprador no requiere reclamar la reducción del precio, sino que él puede reducir ${ }^{68}$; por el contrario, antes de ella solo se le concedía una pretensión de reducción de precio ${ }^{69}$.

Como se ve, en esta materia el $B G B$ siguió con variantes el modelo contenido en la CISG, que contiene un procedimiento de cálculo matemático en su artículo 50, como asimismo se aprecia en el artículo 9:401 de los PECL y en el Draf Common Frame of Reference, cfr. III. 3:601.

En efecto, el artículo 50 de la CISG establece que el comprador podrá rebajar el precio proporcionalmente a la diferencia existente entre el valor que las mercaderías efectivamente entregadas tenían al momento de la entrega y el valor que habrían tenido en ese momento mercaderías conforme al contrato. En ese orden, se denota una primera diferencia con el sistema que se contiene en el $B G B$, pues este último alude al tiempo de celebración del contrato y no al de la entrega. Sin embargo, un autor considera que atendido que en el derecho alemán el comprador se hace dueño con la entrega tratándose de bienes muebles, y que respecto de los inmuebles se requiere además inscripción -de acuerdo a lo establecido en los $\S 446$ y $\S 873-$, el sistema del $B G B$ terminaría siendo idéntico al de la CISG, pues recién ahí se transmite el riesgo al comprador $^{70}$, aunque esta opinión puede ser discutible ${ }^{71}$. Como ha sido comentado, la referencia al momento de la entrega, y no de la conclusión o celebración del contrato, es relevante en la medida en que se hayan producido diferencias de precios en el mercado entre ambas épocas ${ }^{72}$. A su turno, de acuerdo al mismo

\footnotetext{
67 EHMANN, Horst y SuTSCHET, Holger (2006): La reforma del BGB. Modernización del derecho alemán de obligaciones. (Traducc. Claudia López Díaz y Ute Salach de Sánchez, Bogotá, Universidad de Externado de Colombia), p. 262. Discutiblemente, los autores sustentan que el peritaje puede ser una oportunidad para tomar en consideración los gastos de reparación de la cosa viciada, como veremos más adelante.

68 ZimmermanN, Reinhard (2008): El nuevo derecho alemán de obligaciones. Un análisis desde la Historia y el Derecho comparado. (Traducción Esther Arroyo i Amayuelas, Barcelona, Bosch), pp. 107 y 128.

${ }^{69}$ Sobre la reducción del precio en la compraventa antes de la reforma al $B G B$ en materia de obligaciones, véase EnNeCCERUs, Ludwig (1948): Tratado de derecho civil. Derecho de obligaciones (Buenos Aires, Bosch, Publicaciones Jurídicas) Volumen II, p. 62 y HedemanN, J.W. (1958): Derecho de obligaciones (Madrid, Editorial Revista de derecho privado), Volumen III, pp. 267-268.

70 FerRante, Alfredo (2012): La reducción del precio en la compraventa (Navarra, Thomson Reuters, Aranzadi), p. 209.

71 En nuestro país, una referencia al sistema germánico, Peñallillo Arévalo, Daniel (2008): "Sistemas de transferencia de bienes y protección del tráfico", en: Andrés Cuneo (coord.), Estudios de derecho privado. Libro homenaje al profesor Gonzalo Figueroa Yáñez (Santiago, Editorial Jurídica de ChileFundación Fernando Fueyo Laneri), pp. 402-403.

72 López López, Ángel (1997): “Comentario artículo 50", en: Luis Díez Picazo y Ponce de León (dir.), La compraventa internacional de mercaderías. Comentario de la Convención de Viena (Navarra, Thomson Civitas), pp. 448-449. A mayor abundamiento, este tipo de métodos de cálculo permiten distinguir dos
} 
artículo 50, la reducción del precio no podrá ser llevada a efecto si el vendedor ofrece subsanar el incumplimiento conforme al artículo 37, o al artículo 48 si el comprador se niega a aceptar el cumplimiento por el vendedor de acuerdo a esas dos disposiciones. El sistema de cálculo, entonces, supone multiplicar el valor del bien no conforme por el precio estipulado, y luego dividir ese valor por el monto del valor del bien conforme; de dicha operación resulta el valor en que el precio deberá ser rebajado.

Por su parte, el artículo 9:401 de los PECL, establece que la rebaja del precio se calcula determinando la diferencia entre lo que haya disminuido el valor de la prestación en el momento en que se produjo el ofrecimiento y el que hubiera tenido un ofrecimiento conforme. Cabe observar que la fórmula es consistente con la posibilidad de aplicar este remedio no solo ante obligaciones de dar, sino de hacer, en tanto la contraprestación pueda ser reducida. Un sistema similar es el contenido en el artículo III-3:601 del Draf Common Frame of Reference ${ }^{73}$.

\section{El sistema adoptado por el derecho chileno}

El derecho nacional, como es natural, adscribe al primer grupo de ordenamientos jurídicos, no proveyendo de un método de cálculo específico. La doctrina ha guardado silencio sobre este extremo, y la jurisprudencia, por su parte, suele aplicar la reducción del precio prácticamente sin considerar mayores antecedentes.

En efecto, si se analizan los fallos pronunciados en nuestro país, es posible apreciar que los tribunales de justicia adoptan dos posturas: la primera, rechazan la demanda de rebaja de precio si la actora no señala específicamente el monto

formas para ser aplicado, el primero que se denomina "absoluto", con dos variantes: una que supone pagar al comprador la diferencia entre el precio estipulado en el contrato y el valor objetivo de la cosa; y la otra, en que se determina la disminución del precio tomando la diferencia de valores objetivos de la cosa, uno que se fija en relación a su valor ideal, y otro sobre el que ella tiene efectivamente. El método "relativo", en cambio, consiste en determinar el menor valor que da el precio reducido, en referencia a la relación que existe en el momento de la venta entre el valor de la cosa en el estado que ella debería haber tenido, y el que corresponde a su calidad real.

73 III-3:601: Right to reduce price (1) A creditor who accepts a performance not conforming to the terms regulating the obligation may reduce the price. The reduction is to be proportionate to the decrease in the value of what was received by virtue of the performance at the time it was made compared to the value of what would have been received by virtue of a conforming performance. (2) Acreditor who is entitled to reduce the price under the preceding paragraph and who has already paidasum exceeding the reduced price may recover the excess from the debtor.

(3) A creditor who reduces the price cannot also recover damages for the loss thereby compensated but remains entitled to damages for any further loss suffered.

(4) This Article applies with appropriate adaptations to a reciprocal obligation of the creditor other than an obligation to pay a price. 
cuya reducción solicita ${ }^{74}$, razón por la cual los demandantes optan por solicitar la reducción del precio valorándola en sumas aleatorias, sin mayor sustento en el libelo; y la segunda, es que si la demandante indica una suma en que el precio del contrato debe ser reducido, dicho valor se considera en forma meramente referencial, y luego se procede a cuantificar la rebaja discrecionalmente.

Así, a la hora de rebajar el precio, y en una visión panorámica a la jurisprudencia chilena, se advierte dos formas de proceder: o se reduce el precio en una cantidad determinada, usualmente en pesos chilenos, o ella se calcula en porcentajes sobre el precio acordado. En el primer caso encontramos numerosos fallos, como en sentencia pronunciada por la Corte Suprema con fecha 6 de agosto de 2009, rol $N^{\circ} 3349 / 08$, en que se solicitaba se declarare que no correspondía el pago del total de la renta pactada de cuatrocientos cincuenta y dos mil cuatrocientos ochenta y cinco pesos, mientras se prolongaran las obras de un inmueble que fue arrendado para funcionar como local comercial, lo que fue acogido ${ }^{75}$; sentencia de la Corte Suprema de 18 de enero de 2011, rol № 3216/2006, en que se ejerció acción quanti minoris en un contrato de compraventa de inmueble, solicitando la rebaja del precio en un millón quinientos mil pesos, debido a la plaga de termitas que lo afectaba, lo que también fue acogido $^{76}$; algo similar se aprecia en fallo pronunciado por la Corte Suprema

\footnotetext{
${ }_{74}$ Así se aprecia en el considerando décimo de la sentencia de reemplazo pronunciada por la Corte Suprema, en fallo de fecha 4 de agosto de 2008, caratulada "Servicios de impresión J.A. Amenábar Ltda. con Iván, M. Fuentes Riquelme", que ya citamos, y que expresa: "Que en cuanto a la rebaja del precio pactado, consta del libelo que contiene la demanda que, si bien la actora construye sus argumentaciones sobre la base de tal pretensión, olvida indicar finalmente y con exactitud el monto al cual solicita sea reducido el precio acordado, limitándose a realizar tal despliegue únicamente en relación con la indemnización de perjuicios que también persigue. Luego, tal motivo resulta suficiente para desestimar la demanda en aquel capítulo, desde que cualquier apreciación que pudiere hacer el tribunal en tal sentido podría considerarse como un obrar extralimitado de las facultades que le corresponden y que han quedado restringidas por las partes en sus escritos fundamentales". Obsérvese, que la Corte exige que la demandante, entonces, explicite "con exactitud el monto", no bastando en el caso en comento, con el hecho que la actora haya solicitado la rebaja en consideración al mal estado de la máquina comprada.

${ }^{75}$ Causa Gladis Manzur y Compañía Limitada con Ilustre Municipalidad de San Felipe (2009): Corte Suprema, 6 de agosto de 2009 (casación en el fondo), Microjuris № 20909. En este caso, la arrendataria de unos locales comerciales demanda solicitando que se declare que no está obligada a pagar la renta durante todo el tiempo que dure la turbación de su derecho, renta que ascendía a la suma de $\$ 452.485 .-$, además de que se le indemnice por lucro cesante la suma de $\$ 12.000 .000$.- Funda su demanda en que la arrendadora lleva a cabo obras de remodelación en el inmueble arrendado sin haberle dado aviso, que en el marco de esas obras se instalaron mallas raschel, tapando la fachada completa de los locales comerciales, lo que ocasionó la dificultad de exhibir sus productos e impidió el acceso de los clientes.

${ }^{76}$ Causa Sepúlveda Zapata, Irma con Seguel Arratia, Víctor (2011): Corte Suprema, 18 de enero de 2011 (casación en el fondo), vlex 333040446, en este caso, el precio del inmueble se convino en la suma de \$6.000.000.- y la demanda que se interpone en lo principal es únicamente la de indemnización
} 
el 5 de octubre de 2011, causa rol № 8441/2011, pues se pidió la rebaja del precio de venta de un inmueble en treinta y cinco millones de pesos, debido a problemas de humedad y filtraciones, el tribunal accedió a una reducción de veinticinco millones por sobre el precio originalmente acordado ${ }^{77}$. En sentencia de la Corte Suprema de 10 de diciembre de 2013, rol № 260/2011, nuevamente la rebaja de precio demandada se confiere en una suma alzada que asciende a cinco millones de pesos ${ }^{78}$. En el segundo grupo, la rebaja se realiza a través de porcentajes respecto del precio de acordado en el contrato, como en sentencia de 11 de abril de 2002 de la Corte Suprema, causa rol No 986/2001, que ordenó la reducción del precio de la compraventa de dos inmuebles adquiridos por el demandante, suma que se cuantificó en un diez y un quince por ciento, respectivamente, sobre el valor total del precio, equivalente a la suma de 151 y 314 Unidades de Fomento al valor vigente a la fecha de restitución, más intereses contados desde la sentencia ${ }^{79}$; la dictada por la Corte de Apelaciones de La Serena de fecha 4 de enero de 2005, causa rol No $1013 / 2004^{80}$, en este caso los actores dedujeron en lo principal acción redhibitoria, y en subsidio acción de rebaja de precio, la que cuantificaron en un ochenta por ciento del precio acordado, además de la indemnización de los perjuicios por daño emergente, lucro cesante y daño moral, en contra de la empresa constructora, fundada en graves defectos de construcción, como hundimientos de pisos, desprendimientos de cielos y paredes quebradas. La Corte de Apelaciones acogió parcialmente la demanda ordenando la disminución del precio en un treinta por ciento, salvo en el caso de un comprador, cuya rebaja se ordenó en un cuarenta por ciento, rechazando la demanda indemnizatoria. Así, también, en sentencia de fecha 28 de septiembre de 2011, dictada por la Corte Suprema, causa rol No 1474/2010,

de perjuicios, en tanto que la quanti minoris se ejerce con el carácter de subsidiaria. La sentencia definitiva desestima la pretensión indemnizatoria, procediendo a acoger la rebaja demandada y ordena la restitución de la suma de \$1.500.000.-, pues el precio se había pagado íntegramente, fundado en que el bien igualmente sirve, al menos, imperfectamente.

77 Causa Piddo Mujaes, Juan Miguel con Cabezón López, Rafael Nicolás (2011): Corte Suprema, 5 de octubre de 2011 (casación en el fondo), vlex 326783883, en que la compradora interpone en forma conjunta a la acción de rebaja de precio, acción de indemnización de perjuicios. Esta última se acoge sólo en cuanto se condena a resarcir el daño moral, el que se avalúa en la suma de \$10.000.000.-

${ }^{78}$ Causa González Díaz, Myriam con Inversiones y Rentas Mediterráneo y Ltda. (2013): Corte Suprema, 10 de diciembre de 2013 (casación en el fondo).

${ }^{79}$ Causa Vergara Beltrán, Enrique con Inv. Andalien S.A. (2002): Corte Suprema, 11 de abril de 2002 (casación en el fondo), vlex 32031316.

${ }^{80}$ Causa Gamboa Cornu, Jorge con Constructora Pedro Antonio Gallardo Contreras y otro (2005): Corte de Apelaciones de La Serena, 4 de enero de 2005 (casación en forma y apelación), vlex 30923286. 
que conoció de una demanda de rebaja de precio que se cuantificó por la actora en la mitad del precio convenido ${ }^{81}$.

Esta forma de proceder parece cuestionable, debido a la ausencia de criterios definidos que permitan a las partes conocer las razones que llevaron al juez a valorar la reducción objeto del litigio, lo que cobra especial relevancia atendido que la acción de rebaja proporcional del precio o quanti minoris es de gran aplicación práctica, siendo interpuesta por los operadores jurídicos tanto en forma principal, como subsidiaria de la acción redhibitoria, y corrientemente en forma conjunta a la indemnizatoria.

\section{De los parámetros: en la búsqueda de un mecanismo de cálculo en el ordenamiento jurídico nacional}

\subsection{La proporcionalidad}

El Código Civil chileno consagra expresamente en el artículo 1857 un primer elemento a considerar para proceder a la rebaja del precio, pues ella ha de ser proporcional "por los vicios ocultos de la cosa vendida, raíz o mueble", a diferencia del Code en que, recordemos, no hay referencia a la proporcionalidad, y como si la hay en el Código Civil español ${ }^{82}$. Matemáticamente, la proporcionalidad implica la relación entre magnitudes medibles o, en otros términos, la conformidad o proporción de unas partes con el todo, o de elementos entre sí. En este caso, hay dos magnitudes medibles que se contienen en nuestra normativa: el precio y el valor de la cosa por los vicios ocultos. El precio está constituido, por definición, por la suma de dinero que las partes han acordado que el comprador de por la cosa, de manera tal que, a diferencia de algunos sistemas de cálculo contenidos en otras normativas como en la CISG -en que

\footnotetext{
${ }^{81}$ Causa Valenzuela Hidalgo, Ruperto y otros con Inmobiliaria Petrohué y otra (2011): Corte Suprema, 28 de septiembre de 2011 (casación en el fondo), vlex 333762502. En este caso se solicitó la rebaja del precio en la mitad del que se había acordado, equivalente a cuatrocientas unidades de fomento por un valor de siete millones cuatrocientos cuarenta y tres mil setecientos treinta y dos pesos, al 26 de junio de 2007, más la indemnización por daño moral que avalúa en cinco millones de pesos, por cada uno de los 51 demandantes, debido a que los inmuebles padecerían de humedad de condensación, construcción y/o infiltración de agua Iluvia. El debate giró especialmente en la procedencia de las acciones deducidas en contra de la empresa constructora, primera vendedora, pues la demandada consideraba que la acción pertinente es la contenida en el artículo 18 de la Ley General de Urbanismo y Construcción. La Corte estima que la interposición de esta última es incompatible con las edilicias, no obstante, se declara, como en otras causas, que el demandante puede optar entre ejercer estas últimas o aquella contenida en la Ley General de Urbanismo y Construcción. Sin embargo, se desestima el recurso de casación en el fondo, por lo que la demanda se rechaza en todas sus partes.

${ }^{82}$ A la misma proporcionalidad alude el artículo 1928 en sede de arrendamiento.
} 
se discute si ese en un valor que debe considerarse $-^{83}$, en nuestro derecho no hay duda de que es el punto de partida sobre el que ha de verificarse la rebaja. El segundo valor medible es el de la cosa debido a los vicios ocultos que ella presenta. Es cierto que este parámetro puede generar alguna dificultad si se le considera objetivamente, puesto que si el comprador hizo un buen negocio y obtuvo un precio por debajo del valor de mercado del bien, podría darse el caso que el valor objetivo de la cosa con el vicio correspondiere al precio acordado, en cuyo caso no habría reducción alguna, o incluso que dicho valor fuere superior al precio pactado, Ilegándose a la misma solución. En ambos casos, el comprador carecería de interés para demandar una reducción del precio. Sin embargo, nos parece que la forma de corregir este inconveniente es considerar el valor que efectivamente tiene para el comprador la cosa, atendida la funcionalidad que pretende asignarle, más que un valor abstracto y objetivo, lo cual es coherente con la libertad contractual que preside las relaciones entre privados. Con ello, probada la circunstancia del defecto de la cosa, necesariamente se podrá obtener una reducción o rebaja del precio.

\subsection{La gravedad del vicio}

Como señalamos líneas atrás, uno de los aspectos en que se diferencia nuestro Código Civil con el sistema de acciones edilicias contenido en el Code, es que de conformidad al artículo 1868 del primero, en caso de que el vicio no tenga la importancia que se expresa en el artículo $1858 \mathrm{~N}^{\circ} 2$, el comprador solo podrá solicitar la reducción o rebaja del precio. De modo tal, que no se presentaría en el texto el problema que se produce en otras legislaciones, como en la francesa y española, según comentamos, en orden a que si el vicio no es grave no es posible ejercitar ninguna de las acciones protectoras al comprador -redhibitoria y quanti minoris-, dificultad que se soluciona acudiendo a la categoría del "vicio en germen" al momento de la compraventa. La solución original de Bello en esta materia, nos parece, hace innecesario acudir a esta idea del germen del vicio, aunque la doctrina nacional tienda a acogerla sin mayores reparos ${ }^{84}$.

\footnotetext{
${ }^{83}$ FerRante, Alfredo (2011): "Nuevas tendencias en la cuantificación de la reducción del precio", en: Revista para el análisis del derecho (Volumen IV), pp. 43-44.

${ }^{84}$ Así, AlesSandri Rodríguez, Arturo (2011): De la compraventa y de la promesa de venta (Santiago, Editorial Jurídica de Chile), tomo segundo, p. 190. Meza Barros, Ramón (2010): Manual de Derecho Civil. De las fuentes de las obligaciones. Tomo I (Santiago, Editorial Jurídica de Chile), p. 73. Cabe advertir que al momento de explicar la figura de un vicio en germen, acude a lo fallado por la Corte de Casación francesa. Por su parte, la jurisprudencia nacional también adhiere a la idea del germen del vicio al tiempo del contrato, pero sin mayores reflexiones, como se evidencia en el considerando quinto del fallo pronunciado por la Corte Suprema en Aguilera Reyes, Máximo con Inmobiliaria y
} 
Por lo anterior, es que es posible concluir que la elección a que refiere el artículo 1860, en tanto los vicios redhibitorios permiten al comprador elegir ejercitar, ya la acción redhibitoria, ya la quanti minoris, solo es posible en la medida que el vicio sea de aquellos cuya gravedad haga de presumir que el comprador no habría celebrado el contrato. Por el contrario, si el vicio en la cosa es de aquellos que de haberlos conocido el comprador igualmente la hubiera comprado, pero a menor precio -segunda parte del número 2 del artículo 1858-, sólo debiere permitírsele demandar la rebaja proporcional del precio, pues se trata de vicios menos graves ${ }^{85}$.

Una interpretación diversa haría del todo irrelevante la norma contenida en el artículo 1868, y conduciría al mismo problema a que se enfrentan las legislaciones que no establecen una norma similar a ésta. Debemos reconocer que esta forma de coordinar las disposiciones contenidas en los artículos 1858,

Constructora Lago Ranco Limitada (2012): Corte Suprema, 4 de octubre de 2012 (casación en el fondo), vlex 436012946, de hecho en esta causa solo se dedujo acción de rebaja de precio, la que fue acogida ordenando la reducción del precio de compraventa de cuatro inmuebles contaminados con una plaga de termitas, en un veinte por ciento del precio pagado.

85 Desde luego que respecto de vicios que hemos calificado de menos graves, hay una mayor probabilidad que se estime derechamente que no tienen la calidad de vicio o defecto en la cosa, problema que, en rigor, ha de resolverse procesalmente, especialmente rindiendo la prueba necesaria al efecto, como en sentencia Nash Báez, Gladys con Molina Morel Inmobiliaria Construcción (2012): Corte Suprema, 10 de enero de 2012 (casación en el fondo), Microjuris № 30693, en que se desecha la demanda de rebaja del precio, debido a que no se estaría en presencia de un vicio que genera como consecuencia que la cosa no sirve para su uso natural, o solo sirve imperfectamente. El caso versa sobre una compraventa de un departamento en la comuna de Las Condes, en cuya negociación se habría ofrecido por el vendedor una "vista despejada desde el inmueble, de las Avenidas Alonso de Córdova y Presidente Riesco", en circunstancias que al mes de celebrado el contrato, el comprador se entera que se levantaría un edificio de veintiún pisos, por lo que no se mantendría la vista despejada en las condiciones ofrecidas, hecho que no fue puesto en conocimiento al comprador. Si bien la Corte Suprema no entra directamente al fondo del asunto, atendido que no se habría denunciado la infracción a leyes reguladoras de la prueba, pues el conflicto se basa en si efectivamente el vicio que se denuncia cumple con los requerimientos contenidos en el artículo 1858, la Corte hace suyas las concusiones de los jueces del fondo, y declara que "los jueces del fondo definen que para tener como de alta relevancia en la toma de decisión de comprar esa circunstancia puntual en que la demandante basa el vicio que sustenta su pretensión, supone ciertos antecedentes de lógica, sentido común e información o conocimiento del comprador. Al respecto, advierten que, atendida la ubicación geográfica del inmueble; la explicitación por parte de la demandada del proyecto inmobiliario en el inmueble vecino; el precio de compraventa del contrato cuya rebaja se solicita y la explicitación del determinante interés de la actora en adquirir un inmueble con una vista despejada hacia la cordillera, hacen concluir que la cosa objeto del contrato de marras no es de mala calidad ni defectuosa, a lo que se suma el que la demandada haya manifestado la pretendida construcción de uno o más edificios en el terreno adyacente en referencia, hecho que la demandante declaró conocer al concurrir a la celebración de la compraventa. Todo lo anterior, unido al nivel educacional de la demandante -quien declara ser ingeniero en administración de empresas-y el monto de la transacción, llevan a los jueces del mérito a concluir que el departamento adquirido por aquella se realizó respecto de una cosa que no adolecía ningún tipo de vicio, entendiendo por tal la mala calidad o defecto en la cosa". 
1860 y 1868 puede ser discutible, pues con la sola lectura de las dos primeras se da a entender que si el vicio es menos grave, el comprador igualmente cuenta con la posibilidad de optar entre las dos acciones; empero, la adición del artículo 1868 por el legislador es determinante para sustentar que hay un claro distingo entre vicios graves y vicios menos graves, en tanto los segundos solo permiten la reducción del precio. Ciertamente que habría sido deseable que Bello precisara que solo aquel vicio que es de mayor entidad posibilita la elección entre las acciones edilicias, pero al parecer optó por mantener en los artículos 1857 y 1860 redacciones análogas a las de los artículos 1641 y 1644 del Code.

Lo anterior, significa que en nuestro sistema la consideración de la gravedad del vicio es determinante en dos sentidos: disciplina la o las acciones edilicias susceptibles de ser ejercitadas; y para el caso de la acción de rebaja de precio, fija un estándar que debe a ser considerado para llevar a cabo la cuantificación de la rebaja demandada.

\subsection{Los costos de reparación del bien}

En ocasiones, nuestra jurisprudencia ha acudido al monto de la reparación del bien defectuoso como elemento a considerar en la cuantificación de la reducción del precio, ya sea como un único antecedente para ello, o ligado a otros elementos de juicio ${ }^{86}$. Algo similar se aprecia en la jurisprudencia extranjera ${ }^{87}$.

\footnotetext{
${ }^{86}$ Así, por ejemplo, en causa Spataris Schaffhauser, Aquiles con Sociedad Comercial Automotriz La Portada y Lunas Casas, Alejandro (2007): Corte Suprema, 25 de julio de 2007 (casación en el fondo), se demanda rebaja del precio en una compraventa de un automóvil, que la demandante cuantifica en un millón quinientos mil pesos, y que corresponderían a los costos de reparación del mismo, más indemnización de perjuicios. La Corte Suprema en fallo de fecha 25 de julio de 2007, rechaza el recurso de casación interpuesto por la demandada, por lo que queda a firme la sentencia dictada por la Corte de Apelaciones de Santiago de 16 de noviembre de 2005, que acogió la demanda de reducción del precio en los términos solicitados, sin mayores disquisiciones sobre la cuantificación efectuada por la actora. En causa caratulada "Aguilera Reyes, Máximo con Inmobiliaria y Constructora Lago Ranco", ya citada, el valor en que se ordena la reducción del precio asciende al veinte por ciento del precio fundada, según el tribunal, en que "los sentenciadores estimaron indiciaria la tasación o avaluación practicada por el informe y pericia de fojas 10, ratificada a fojas 430, y los dichos de los testigos de las partes, concluyendo que el costo del trabajo respecto de las doce casas del condominio, durante solo un año, ascendió a \$2.430.000.- más impuesto IVA, para dar luego lugar al pago de una mantención anual por US 675.- más IVA. De ello se desprende que el costo porcentual del control y monitoreo por cada una de las viviendas durante solo tres años debería ascender a \$202.500.- más US 112.-, todo ello más impuesto IVA, regulando la rebaja en tal virtud, considerando tales costos mínimos actualizados como indiciarios de la depreciación de los inmuebles sin incluir daños mayores eventualmente ya producidos o sobrevinientes, los sentenciadores regularon en un veinte por ciento la parte del precio de compraventa pagado a rebajar por cada inmueble".

${ }^{87}$ Como se puede constatar en sentencia de 18 de octubre de 2005, pronunciada por la Audiencia Provincial de Alicante, ya mencionada, en que el precio se rebaja en una suma de 1.125, correspondiente
} 
Sin embargo, se trata de un factor del todo discutible, como se evidencia en la doctrina foránea ${ }^{88}$, especialmente por dos razones: la primera, es que el costo de las reparaciones no atiende a la naturaleza de la acción quanti minoris, cuyo supuesto de hecho es la existencia de un vicio o defecto que impide la funcionalidad de la cosa, por lo que la sola consideración al valor a que asciende su reparación es reduccionista, en tanto no permite apreciar en forma integral el interés que tiene el acreedor respecto de dicha $\cos ^{89}$; la segunda, porque la referencia a la reparación del bien se encuentra vinculada con un modelo que no está acogido en códigos civiles como el francés ${ }^{90}$, el español y, ciertamente, el nuestro, debido a que en estos ordenamientos jurídicos el esquema regulatorio tiene por objeto una obligación de dar una especie o cuerpo cierto, de modo que el objeto debido es ese y no otro, de ahí que no sería posible exigir al vendedor la subsanación de los defectos que presenta la misma, sino que en ese caso surge su obligación de saneamiento ${ }^{91}$. Por el contrario, el deber de reparar y de sustituir el bien por otro, es propio de aquellos sistemas jurídicos en que el vendedor se obliga a entregar una cosa conforme, como en la CISG $^{92}$ que, a su turno, constituye una modalidad que puede asumir el cumplimiento específico, y que se explica porque a pesar de que con esas medidas no se cumple estrictamente con el deber primario de la prestación, igualmente el acreedor ve satisfecho su interés a través del cumplimiento en naturaleza ${ }^{93}$.

al costo de las reparaciones del inmueble, debido a la humedad generada por filtraciones. También en sentencia № 164/2009: Audiencia Provincial de Navarra (apelación), vlex 210540311.

88 De Verda y BeAmonte, José (2009): Saneamiento por vicios ocultos. Las acciones edilicias (Navarra, Aranzadi Thomson Reuters), pp. 303-304.

${ }^{89}$ FerRante, Alfredo (2012): La reducción del precio en la compraventa (Navarra, Thomson Reuters, Aranzadi), pp. 154-166.

${ }^{90}$ A pesar de ello, algunos tratadistas franceses desde antiguo han sostenido que aunque el Code no contempla la posibilidad de que el comprador solicite la reparación de la cosa, ella emanaría de los principios generales que obligan al vendedor a garantir al comprador el pacífico y útil goce de la cosa. Baudry-Lacantinerie, G. y Saignat, Léo (1900): Droit civil. De la vente et de l'échange (París, Librairie de la Société du Recueil G des Lois et des Arréts), p. 370. Agregan que las acciones redhibitoria y estimatoria no eliminan la facultad que resulta del derecho común, pero con una restricción, el comprador no puede exigir la reparación de la cosa si ello es imposible, o si es posible, se considera imposible si ella implica costos que no la hacen proporcional en relación al valor de la misma.

91 Morales Moreno, Antonio (2006): La modernización del derecho de obligaciones (Madrid, Aranzadi S.A.), pp. 192-193.

92 Morales Moreno, Antonio (2012): "Tres modelos de vinculación del vendedor en las cualidades de la cosa", en: Anuario de derecho civil (fascículo I), p. 19.

93 LÓPEZ López, Ángel (1997): “Comentario artículo 50", en: Luis Díez Picazo y Ponce de León (dir.), La compraventa internacional de mercaderías. Comentario de la Convención de Viena (Navarra, Thomson Civitas), p. 415; Morales Moreno, Antonio (2006): La modernización del derecho de obligaciones (Madrid, Aranzadi S.A.), p. 82; Morales Moreno, Antonio (2012): "Tres modelos de vinculación del vendedor 
Por lo anterior, es que efectivamente en el marco de la regulación contenida en el Código Civil chileno no pueda exigirse al vendedor la reparación de la cosa defectuosa ${ }^{94}$, pero cuestión distinta es preguntarnos si es posible recurrir al valor de las reparaciones como una pauta en la determinación de la reducción del precio, pues nos parece que no hay inconveniente alguno en utilizar este criterio para cuantificar la rebaja demandada, a menos que tales costos sean superiores al precio acordado, pues en tal caso se contraviene la finalidad perseguida con el ejercicio de la acción quanti minoris. Destaquemos, además, que tales costos también son susceptibles de ser incorporados dentro de los ítems a ser resarcidos en una demanda de indemnización de los perjuicios derivados del vicio o defecto en la cosa.

\section{El sistema contenido en los Principios latinoamericanos de derecho de contratos}

Recientemente, fueron presentados por un grupo de prestigiosos académicos chilenos y de otros países de habla hispana, los denominados "Principios latinoamericanos de derecho de los contratos", en adelante, PLDC ${ }^{95}$, que contemplan una disposición referida a la reducción del precio, en los siguientes términos: "En caso de cumplimiento imperfecto, el acreedor puede aceptarlo y reducir el precio en proporción a la diferencia entre el valor que la prestación ejecutada tenía al tiempo en que se realizó y el que habría tenido en ese mismo momento, si hubiese existido cumplimiento.

La reducción del precio es incompatible con la indemnización del menor valor de la prestación.

en las cualidades de la cosa", en: Anuario de derecho civil (fascículo I), p. 20. En efecto, el artículo 46.3 de la CISG dispone: "Si las mercaderías no fueren conformes al contrato, el comprador podrá exigir que las repare para subsanar la falta de conformidad, a menos que esto no sea razonable habida cuenta de todas las circunstancias. La petición de que se reparen las mercaderías deberá formularse al hacer la comunicación a que se refiere el artículo 39 o dentro de un plazo razonable a partir de ese momento". El artículo 7.2.3 de los Principios Unidroit también consagran estas modalidades que puede asumir el cumplimiento específico, a diferencia de los PECL, aunque la doctrina estima que estas medidas están implícitas en el artículo 9:102.1, no obstante que la disposición expresamente refiere a la reparación. BECH SERRAT, Josep (2010): "Reparar y sustituir cosas en la compraventa: evolución y últimas tendencias", en: Revista para el análisis del derecho. Girona: Facultad de Derecho Universidad de Girona, p. 13.

${ }_{94}$ No así en la reglamentación contenida en la Ley General de Urbanismo y Construcciones y en la Ley sobre Protección a los Derechos de los Consumidores, pues en ambos casos se considera la pretensión de obtener la reparación del bien por parte del demandado.

95 Morales Moreno, Antonio (2014): "Los Principios latinoamericanos de derecho de los contratos. Un debate abierto sobre las grandes cuestiones jurídicas de la contratación", en: Anuario de derecho civil (fascículo I), p. 229. 
En todo caso, el acreedor puede demandar la indemnización de cualquier otro daño".

Nos interesa esbozar algunos comentarios preliminares respecto de esta norma, no solo en lo que refiere a la fórmula que se acoge para proceder a la rebaja, sino también observaciones de carácter más general, precisamente porque ello puede incidir en el método de cálculo que se propone.

En primer término, es evidente que esta disposición se encuentra en consonancia con la tendencia a generalizar la rebaja del precio a aquellos contratos que por su naturaleza ello es posible, como ya hemos señalado. Esto es, ha de tratarse de un contrato con prestaciones recíprocas, en que ante un cumplimiento defectuoso de una parte, la contraparte insatisfecha estará facultada para reducir el precio. En segundo lugar, también en línea con la doctrina contemporánea, no sería necesario proceder a la reducción del precio por la vía judicial, puesto que la norma posibilita que sea el acreedor el que proceda a practicar la rebaja, si a su juicio el deudor ha dado lugar a un cumplimiento imperfecto ${ }^{96}$. De acogerse este sistema, lo más probable es que la rebaja del precio se transforme en un remedio mucho más eficiente, puesto que sólo se arribará a una contienda judicial en caso que el deudor intente probar que el incumplimiento que se le atribuye no es tal, o bien, si no está de acuerdo con la cantidad en que se cuantifica la reducción.

Desde la perspectiva de nuestro sistema jurídico, una norma como la que acabamos de transcribir supone un cambio de paradigma respecto de la naturaleza de la rebaja proporcional del precio. En efecto, ya no estaríamos en presencia de una acción derivada de la obligación de saneamiento que pesa sobre comprador o arrendador, sino que tendría el carácter de un remedio más ante el incumplimiento contractual, que se caracterizaría por ser aplicado, al menos inicialmente, en sede extrajudicial, por medio de una reestructuración de las prestaciones de las partes, tendiente al equilibrio entre ellas. En ese sentido, completaría el sistema de derechos con que cuenta el acreedor insatisfecho.

En seguida, en lo que refiere al sistema de cálculo que la disposición sugiere, nos parece que hay varios aspectos positivos que destacar. En primer lugar, es posible percatarse que el sistema que incorpora es prácticamente idéntico a aquel que está incluido en la Propuesta española para la Modernización del derecho de obligaciones y contratos, al que ya hemos referido y que, a la vez, es el que se encuentra contenido en la CISG y en otros instrumentos de derecho

\footnotetext{
96 FeRRANTE, Alfredo (2012): La reducción del precio en la compraventa (Navarra, Thomson Reuters, Aranzadi), p. 86.
} 
uniforme ${ }^{97}$. Como en esas normativas, según la disposición contenida en los PLDC habría tres valores a considerar en la rebaja: desde luego que el precio estipulado que es el que debería ser reducido, luego, el valor que la prestación ejecutada tenía al tiempo en que se realizó y, finalmente, el valor que habría tenido en ese mismo momento, si hubiese existido cumplimiento. Considerando que los PLDC acogerían el método de cálculo contenido en Viena, respecto del cual hay un grado de consenso entre los comentadores de la CISG, en orden a que en ésta se acoge el método proporcional relativo ${ }^{98}$, sería posible explicar que la fórmula que se acoge en los PLDC, implicaría multiplicar el valor de la prestación ejecutada que tenía al momento en que se realizó -en la propuesta española, sería el valor de la prestación no conforme-, por el precio estipulado en el contrato, y luego dividir ese monto por el valor que habría tenido la prestación de haber existido el cumplimiento.

Un sistema de este tipo presenta varias ventajas, así, toma en consideración la estipulación de las partes representada por el precio acordado y, nos parece, también por el valor de la prestación de haber existido cumplimiento. Pero, especialmente, se debe destacar que el momento a ser considerado en la reducción no sería el de la celebración del contrato, sino aquel en que la prestación defectuosa se realizó; y es que la consideración a ese momento y no al de la celebración del contrato es de toda lógica, puesto que desde ahí el acreedor hace suyas las ventajas que el contrato le proporciona, y es solo desde ese momento que el mismo acreedor puede juzgar si el cumplimiento ha sido imperfecto. Ello, además, posibilita que la rebaja del precio se aplique por la vía extrajudicial, permitiendo al acreedor pagar menor precio que el acordado originalmente, o solicitar la restitución del precio pagado en exceso luego de su reducción.

No obstante, un sistema de cuantificación en la reducción del precio de esta naturaleza también ha sido objeto de algunas críticas, entre ellas, porque se toma como referencia el valor de mercado, que puede ser muy complejo de determinar, y aunque fuere posible en teoría determinarlo en forma exacta, en

\footnotetext{
${ }^{97}$ Fenor PICÓN, Nieves (2011): "La Modernización del régimen del incumplimiento de contrato: Propuestas de la Comisión General de Codificación. Parte primera: Aspectos generales. El incumplimiento", en: Anuario de derecho civil (fascículo I), p. 1563; VIDAL Olivares, Álvaro (2011): "El incumplimiento y los remedios del acreedor en la Propuesta de Modernización del derecho de las obligaciones y contratos español", en: Revista Chilena de Derecho Privado (№ 16), p. 282.

98 LÓPEZ López, Ángel (1997): “Comentario artículo 50", en: Luis Díez Picazo y Ponce de León (dir.), La compraventa internacional de mercaderías. Comentario de la Convención de Viena (Navarra, Thomson Civitas), p. 449.
} 
algunos casos puede ir en contra de la finalidad de la acción quanti minoris, que es volver a un equilibrio prestacional ${ }^{99}$.

\section{Conclusiones}

1.- El Código Civil chileno no contiene un sistema de cálculo aplicable a la acción quanti minoris o de rebaja del precio, lo que ha llevado a los tribunales de justicia a reducir el precio en forma discrecional, ya sea en sumas específicas de dinero, o en porcentajes sobre el precio pactado en el contrato, sin considerar antecedentes de carácter objetivo que permitan a las partes conocer el razonamiento utilizado en la decisión del conflicto.

2.- Las normas contenidas en el Código Civil chileno permiten inferir algunos parámetros o criterios para efectos de proceder a la rebaja del precio. En la identificación de tales criterios es fundamental considerar la naturaleza de la acción, que no es indemnizatoria sino de garantía, y que se caracteriza por restablecer el equilibrio prestacional entre las partes, manteniendo vigente el contrato.

3.- Es posible identificar tres sistemas que los ordenamientos jurídicos adoptan para proceder a la rebaja del precio: un primer grupo está constituido por los ordenamientos que aunque reconocen a la acción quanti minoris, no contemplan un sistema para proceder a la reducción; un segundo grupo, son aquellos sistemas que expresamente refieren al cálculo de expertos o peritos, y finalmente, los que establecen un método de cálculo matemático. Esta última opción es la más recurrida en normativas más recientes, especialmente europeas y en algunos instrumentos de derecho uniforme, entre los que destaca el artículo 50 de la CISG.

4.- Nos parece que los criterios que pueden ser adoptados en el derecho nacional, a falta de un método aritmético de cálculo, son principalmente: la proporcionalidad, la gravedad del vicio y, en ciertos casos, el valor de la reparación del bien. El criterio de la gravedad del vicio es especialmente relevante, atendido que el Código Civil chileno solo faculta obtener la reducción del precio, si el vicio o defecto en la cosa es menos grave.

5.- Es destacable la iniciativa de incorporar en los PDLC una norma que reconoce la rebaja del precio como un derecho o remedio de aplicación general, además de integrar un método de cálculo matemático que sigue la línea del derecho uniforme.

99 FerRante, Alfredo (2012): La reducción del precio en la compraventa (Navarra, Thomson Reuters, Aranzadi), pp. 267-269. Agrega el autor, que los problemas se presentarán especialmente en los casos de aliud pro alio y en ventas en rebajas o tratándose de productos de segunda selección. 